Cite this: RSC Advances, 2013, 3, 4350

Received 31st October 2012,

DOI: $10.1039 / c 3 r a 22712 j$

www.rsc.org/advances Accepted 17th January 2013

\section{Emission spectroscopy of uranium(Iv) compounds: a combined synthetic, spectroscopic and computational study $\dagger$}

\author{
Emtithal Hashem, ${ }^{\text {a }}$ Adam N. Swinburne, ${ }^{b}$ Carola Schulzke, ${ }^{a}$ Rachel C. Evans, ${ }^{a}$ James \\ A. Platts, ${ }^{* c}$ Andrew Kerridge, ${ }^{\star d}$ Louise S. Natrajan ${ }^{* b}$ and Robert J. Baker*a
}

\begin{abstract}
Emission spectroscopy has been used for the first time in a spectroscopic study of a family of uranium(IV) halide complexes in non-aqueous media. The room temperature electronic absorption spectra of the simple coordination compounds $\left[\mathrm{Li}(\mathrm{THF})_{4}\right]\left[\mathrm{UX}{ }_{5}(\mathrm{THF})\right]\left(\mathrm{X}=\mathrm{Cl}, \mathrm{Br}_{1} \mathrm{I}\right),\left[\mathrm{Et}_{4} \mathrm{~N}_{2}\left[\mathrm{UCl}_{6}\right]\right.$ and $\mathrm{UCl}_{4}$ in $\mathrm{THF}$ have been recorded and all transitions assigned with the aid of a comprehensive computational study using CASSCF and CASPT2 techniques. Excitation into a band of $f-d$ and LMCT character followed by energy transfer into the 5f-orbital manifold accounts for the UV-visible radiative transitions observed in the emission spectra, which have been fully assigned as arising from transitions from the $5 f^{1} 6 d^{1}$ electronic configuration to envelopes of states arising from the ground state $5 f^{2}$ configuration. The bonding in $\left[\mathrm{Li}(\mathrm{THF})_{4}\right]\left[\mathrm{UCl}_{5}(\mathrm{THF})\right]$ has been further elucidated utilising NBO and AIM calculations which describe the nature of the $\mathrm{U}-\mathrm{Cl}$ bond as predominantly ionic with some dative covalent character and substantial overlap between the $\mathrm{Cl}$ $3 p$ orbitals and $5 f$ and $6 \mathrm{~d}$ orbitals on uranium. These studies indicate that the emission spectral fingerprint of simple U(IV) compounds of $O_{h}, C_{4 v}$ and $C_{2 v}$ symmetry are similar and characteristic and may be used as a diagnostic tool to assign U(IV) species in solution and by inference, in the environment, in the presence of $\left[\mathrm{UO}_{2}\right]^{2+}$.
\end{abstract}

\section{Introduction}

Photoluminescence spectroscopy of complexes of the lanthanide(III) metals has had a significant and important impact on materials and bioinorganic chemistry and the physical processes that give rise to these emissions are well known and understood. ${ }^{1}$ Current understanding of the corresponding photoluminescence processes of actinide complexes does not approach this level of sophistication. ${ }^{2}$ The most well defined is the green emission of the uranyl, $\left[\mathrm{UO}_{2}\right]^{2+}$, ion which occurs from deactivation of a formally triplet ligand

\footnotetext{
${ }^{a}$ School of Chemistry, University of Dublin, Trinity College, Dublin, Ireland. E-mail: bakerrj@tcd.i.e.; Fax: +353-1-712826; Tel: +353-1-8963501

${ }^{b}$ School of Chemistry, The University of Manchester, Oxford Road, Manchester, UK. E-mail: Louise.Natrajan@manchester.ac.uk; Fax: +44 (0)1612754616;

Tel: +44 (0)1612751426

${ }^{c}$ School of Chemistry, Main Building, Cardiff University, Park Place, Cardiff, CF10 3AT, U. K.. E-mail: platts@cf.ac.uk; Fax: +44 (0)29 208 74030;

Tel: +44 (0)2920874950

${ }^{d}$ Department of Chemistry, University College London, 20 Gordon Street, London WC1H OAJ, UK. E-mail: a.kerridge@ucl.ac.uk; Fax: +44(0)2076797463;

Tel: +44 (0)2076795814

$\dagger$ Electronic supplementary information (ESI) available: Full electronic absorption and emission spectra and computational assignments, SQUID magnetometry data of $\mathbf{1}$ and VT CV data of $\mathbf{1}$ and 2. CCDC reference number 907974. For ESI and crystallographic data in CIF or other electronic format see DOI: $10.1039 / \mathrm{c} 3 \mathrm{ra} 22712 \mathrm{j}$
}

to metal charge-transfer (LMCT) excited state. Whilst the majority of studies have focused on aqueous compounds, this technique has only recently been applied to non-aqueous uranyl compounds. ${ }^{3}$ What is clear from these studies is that the position of the emission band and the radiative lifetimes can provide valuable insight into the electronic environment at the uranium centre and, more recently, the degree of aggregation in solution. ${ }^{3}$ The later actinide ion $\mathrm{Cm}^{3+}$ (and to a lesser extent $\mathrm{Am}^{3+}$ ) is routinely characterised by timeresolved laser-induced emission spectroscopy in certain laboratories ${ }^{2 \mathrm{c}}$ as the sensitivity of this technique is useful in studying small quantities of these highly radioactive materials in low concentrations. ${ }^{2 \mathrm{a}, 4}$ There is no obvious physical reason why uranium(Iv) compounds should not also show photoluminescence in fluid solution; in solid-state materials (e.g. in cubic $\mathrm{U}^{4+}$ doped $\mathrm{LiYF}_{4}$ and $\mathrm{Cs}_{2} \mathrm{ZrBr}_{6}$ ) there are a number of studies that show emission from the highest energy ${ }^{3} \mathrm{~F}_{2}$ energy charge-transfer excited-state manifold $\left(5 \mathrm{f}^{1} 6 \mathrm{~d}^{1}\right)$ to the RussellSaunders coupled ${ }^{3} \mathrm{H}_{4} 5 \mathrm{f}^{2}$ ground state and higher lying energy states derived from the $5 \mathrm{f}^{2}$ electronic configuration. ${ }^{5}$ Kirishima et al. reported the only comprehensive photoluminescence spectrum of $\mathrm{U}^{4+}$, as the hydrated ion and suggested that the ten emission bands originated from the highest energy ${ }^{1} \mathrm{~S}_{0}$ Russell-Saunders coupled state to the lower lying $5 \mathrm{f}^{2}$ spin-orbit coupled levels. ${ }^{6}$ Interestingly, computational stu- 
dies indicate that when the highest energy term is corrected for a large Stoke's shift (i.e. solvation effects), the assignment of the emission bands changes considerably, ${ }^{7}$ highlighting the fact that the intra $5 f$ electronic transitions are very sensitive to the coordination environment, crystal field and symmetry. ${ }^{6 a}$ The open shell nature of these compounds make the assignment of absorption and emission bands challenging, although analysis based upon the Russell-Saunders coupling scheme can be used as a good approximation. ${ }^{4 \mathrm{~b}}$

In terms of synthetic inorganic and organometallic chemistry, there has been a substantial body of work published on U(IV) compounds, and fundamental studies have given greater insight into the reactivity and electronic structures of these compounds. In particular organometallic compounds have been used as a readily tuneable platform for comprehensive studies on the electronic structure of $\left[\mathrm{Cp}_{2}{ }_{2} \mathrm{AnX}_{2}\right](\mathrm{An}=\mathrm{Th}, \mathrm{U})$. The effect of the $\sigma$ - and $\pi$ - type $\mathrm{X}$ ligands on the electronic and magnetic properties has been thoroughly elucidated in a number of elegant studies. ${ }^{8}$ A probable explanation for the lack of reports on the photoluminescence of U(IV) species is that in general the coordinated ligands possess low energy charge transfer absorptions that can mask $\mathrm{f}-\mathrm{f}$ transitions. This is exemplified by the reports of the metallocene ketimide system $\left[\mathrm{Cp}_{2}{ }_{2} \mathrm{U}\left\{\mathrm{N}=\mathrm{C}(\mathrm{Ph})\left(\mathrm{CH}_{2} \mathrm{Ph}\right)\right\}_{2}\right]$, where no 5 f-centered emission was observed following photoexcitation since decay from the ligand centered singlet state proceeds directly through the 5 f-electron manifold, resulting in efficient quenching of the emission and lifetimes of picosecond order. ${ }^{8 \mathrm{~d}}$ With the correct choice of ligands, we postulate that photoluminescence spectroscopy should be a very useful technique in fingerprinting the +IV oxidation state of uranium, and for further elucidation of the electronic structure of uranium(Iv) compounds that is complementary to conventional absorption spectroscopy. In addition, if U(IV) can be detected in the presence of the uranyl ion, the qualitative and quantitative discrimination of these two oxidation states would have a significant and substantial impact upon the environmental detection of these important ions for example, under nuclear waste repository or soil contamination conditions. There is currently no simple and scalable analytical technique that can do this.

With this in mind, it is noteworthy that Maldivi et al. reported that absorption spectroscopy in trivalent uranium compounds can provide insight into the degree of $5 \mathrm{f}$-orbital participation in bonding to ligands. ${ }^{9}$ The participation of the $5 \mathrm{f}$ and $6 \mathrm{~d}$ orbitals in forming covalent bonds is now of great experimental and theoretical interest. ${ }^{10}$ Enhanced covalency is not just of academic interest as it is also postulated to allow for a methodology to separate the minor actinides $\mathrm{Am}^{3+}$ and $\mathrm{Cm}^{3+}$ from the lanthanides for applications towards current and future nuclear waste streams. ${ }^{11}$ In particular it has been noted that ligands containing softer donor atoms have a higher affinity for trivalent actinides $\left(\mathrm{U}^{3+}, \mathrm{Am}^{3+}, \mathrm{Cm}^{3+}\right)$ over trivalent lanthanides, ${ }^{11 \mathrm{a}}$ and this is thought to be due, in part, to a greater covalent character to the actinide-ligand bond. ${ }^{12}$ However, recent computational studies cast some doubt on the origins of this perceived covalency and suggest that enhancements in separation factors for the isoelectronic pair $\mathrm{Am}(\mathrm{III}) / \mathrm{Eu}$ (III) in particular are due to the coincidental match of ligand and metal orbitals and not enhanced overlap of the f-orbitals. This has been termed "near-degeneracy driven covalency". ${ }^{10 \mathrm{q}}$

A thorough understanding of the electronic structure of the actinides is still lacking in some areas. However it is of great importance since it underpins separation science studies and further experimental and theoretical studies are required to fully understand the subtleties of actinide chemistry. In this contribution we report for the first time the photoluminescent properties of some simple U(IV) coordination compounds that have previously been prepared, viz. $\left[\mathrm{Et}_{4} \mathrm{~N}\right]_{2}\left[\mathrm{UCl}_{6}\right]$ and $\left[\mathrm{UCl}_{4}(\mathrm{THF})_{3}\right]$, and the synthesis and comprehensive characterisation of $\left[\mathrm{Li}(\mathrm{THF})_{4}\right]\left[\mathrm{UCl}_{5}(\mathrm{THF})\right]$. A comprehensive computational study on the electronic absorption and emission spectra of these compounds has been carried out using CASSCF techniques. In addition a thorough analysis of the bonding in the $\mathrm{U}-\mathrm{Cl}$ bond is explored via an NBO (Natural Bond Order) and AIM (atoms-in-molecules) approach.

\section{Results and discussion}

\section{Synthesis and structure}

In order to probe the use of photoluminescence spectroscopy of non-aqueous U(IV) species, simple model compounds are required that have no quenching processes arising from ligands containing aromatic groups or conjugated entities. It occurred to us that the well defined $\left[\mathrm{UCl}_{6}\right]^{2-}$ anion would be a useful starting point; however the high symmetry of this compound may suggest that any formally symmetry forbidden bands would not be seen. A reduction in the symmetry around the metal ion would therefore be more informative. We reasoned that compounds such as $\left[\mathrm{UCl}_{5}(\mathrm{THF})\right]^{-}$and [UCl ${ }_{4}(\mathrm{THF})_{3}$ ] (of $C_{4 \mathrm{v}}$ and $C_{2 \mathrm{v}}$ symmetry, respectively) would be more amenable for our initial studies. The compound $\mathrm{UCl}_{4}$ was prepared as described in the literature and all characterisation data were in agreement with those previously reported. The reaction of $\mathrm{UCl}_{4}$ with one equivalent of dry LiCl in THF, followed by filtration and recrystallisation yielded $\left[\mathrm{Li}(\mathrm{THF})_{4}\right]\left[\mathrm{UCl}_{5}(\mathrm{THF})\right], \mathbf{1}$ in excellent yield as a pale green air sensitive crystalline solid. The structure of this compound has previously been reported as a by-product formed during a salt metathesis reaction. ${ }^{13}$ The analogous compound $\left[{ }^{n} \mathrm{Bu}_{4} \mathrm{~N}\right]\left[\mathrm{UCl}_{5}(\mathrm{THF})\right]$ has also been previously reported. ${ }^{14}$ The corresponding halides $\left[\mathrm{Li}(\mathrm{THF})_{n}\right]\left[\mathrm{UBr}_{5}(\mathrm{THF})\right], \quad 2$, and $\left[\mathrm{Li}(\mathrm{THF})_{n}\right]\left[\mathrm{UI}_{5}(\mathrm{THF})\right], \mathbf{3}$, were prepared by the reaction of $\mathbf{1}$ with $\mathrm{Me}_{3} \mathrm{SiX}(\mathrm{X}=\mathrm{Br}, \mathrm{I})$. Whilst the bromide compound was stable in solution, we found that the iodide was substantially more air sensitive and only mixtures of $\left[\mathrm{UI}_{5}(\mathrm{THF})\right]^{-}$and $\left[\mathrm{UO}_{2} \mathrm{I}_{4}\right]^{2-}$, the latter as the major product, were observed by UV-vis absorption spectroscopy (vide infra), even under rigorously anhydrous and oxygen-free conditions. Hayton et al. have prepared the related compound $\left[\mathrm{H}\left(\mathrm{OEt}_{2}\right)_{2}\right]\left[\mathrm{UI}_{5}\left(\mathrm{OEt}_{2}\right)\right]$ and reported that it decomposes in 
donor solvents, but the nature of this decomposition was not described. ${ }^{15}$ The ${ }^{1} \mathrm{H}$ NMR spectra of $\mathbf{1}$ and $\mathbf{2}$ in pyridine- $\mathrm{d}_{6}$ show the presence of uncoordinated THF suggesting that this ligand is rather labile. Due to this, we have been unable to obtain reproducible elemental analyses as they are consistently low in carbon and hydrogen. There is a single resonance in the ${ }^{7} \mathrm{Li}$ NMR spectra of 1 and 2 in THF at $\delta_{\mathrm{Li}}=-2.64 \mathrm{ppm}$ and $-0.97 \mathrm{ppm}$, respectively, which indicates that in solution they exist as separated ions, as any interaction with the paramagnetic uranium centre would be expected to induce large pseudocontact chemical shifts. The infrared and Raman spectra show bands that can be assigned to the coordinated THF molecule, whilst a U-Cl stretch can be seen at $305 \mathrm{~cm}^{-1}$ in the Raman spectrum. Confirmation of the U(IV) oxidation state comes from the variable temperature and variable field magnetic susceptibility of $\mathbf{1}$, with a region of temperature independent paramagnetism from 300 to $100 \mathrm{~K}\left(\mu_{\mathrm{eff}}=2.04 \mu_{\mathrm{B}}\right.$ at $300 \mathrm{~K}$ ) followed by a precipitous drop in the magnetic moment $\left(\mu_{\text {eff }}=0.40 \mu_{\mathrm{B}} \text { at } 10 \mathrm{~K}\right)^{16}$ (Fig. S1 and S2, ESI $\dagger$ ). This compares well to the magnetic susceptibility recorded for $\left[\mathrm{Ph}_{3} \mathrm{PBu}\right]_{2}\left[\mathrm{UCl}_{6}\right]\left(2.22 \mu_{\mathrm{B}}\right.$ at $\left.295 \mathrm{~K}\right),{ }^{17}$ and lower than the value of $3.38 \mu_{\mathrm{B}}$ expected for a pure ${ }^{3} \mathrm{H}_{4}$ ground state. This reduction in effective moment compared to the free ion at room temperature is common in U(IV) compounds and has been ascribed to quenching of spin-orbit coupling due to covalent metal-ligand interactions.

Crystals of 1 suitable for X-ray diffraction were grown and the metric parameters around the uranium are as reported previously. ${ }^{13,14}$ One interesting structural feature is that the $\mathrm{Cl}_{\mathrm{eq}}-\mathrm{U}-\mathrm{O}$ angles are $85.3^{\circ}$ (average) as the uranium atom sits slightly above the equatorial plane by $0.2 \AA$. The average bond length $(2.60 \AA)$ can be compared to the U(III) compound $\mathrm{K}_{2} \mathrm{UCl}_{5}$ $\left(\begin{array}{ll}2.80 & \AA\end{array}\right)^{18}$ and the $\mathrm{U}(\mathrm{v})$ compound $\left[\mathrm{UCl}_{5}\left(\mathrm{OPPh}_{3}\right)\right]$ (2.47$2.50 \AA) .{ }^{19}$ The expected bond lengths, on the basis of the 6-coordinate ionic radii, ${ }^{20}$ are $2.43 \AA, 2.56 \AA$ and $2.695 \AA$ for $\mathrm{U}(\mathrm{V})$, (IV) and (III) respectively, suggesting the bonding in $\mathbf{1}$ is primarily ionic. The nature of the bonding in $\left[\mathrm{Cp}^{*}{ }_{2} \mathrm{MCl}_{2}\right]^{10 \mathrm{~d}}$ and $\left[\mathrm{MCl}_{6}\right]^{2-}\left(\mathrm{Cp}^{*}=\mathrm{C}_{5} \mathrm{Me}_{5} ; \mathrm{M}^{4+}=\mathrm{Ti}, \mathrm{Zr}, \mathrm{Hf}, \mathrm{Th}, \mathrm{U}\right)^{21}$ has recently been experimentally investigated using $\mathrm{Cl}$ K-edge X-ray absorption (XAS) spectroscopy and for uranium a contribution of $9 \%$ and $18 \% \mathrm{Cl} 3 \mathrm{p}$ orbital are involved in the $\mathrm{U}-\mathrm{Cl}$ bonds, respectively; i.e. a small degree of covalency.

\section{Electronic spectroscopy}

Absorption Spectroscopy. The UV absorption spectra in the range $260-380 \mathrm{~nm}$ of $\mathbf{1}$ and $\mathbf{2}$ in THF are shown in Fig. 1. Looking firstly at the spectrum of $\mathbf{1}$, there are two broad, intense bands in the UV region at $277 \mathrm{~nm}$ and $303 \mathrm{~nm}$ and a shoulder at $331 \mathrm{~nm}$, which are difficult to definitively assign as they could be due to either chloride to uranium charge transfer (CT), THF to uranium charge transfer or $\mathrm{f} \rightarrow \mathrm{d}$ transitions, all of which would be formally allowed and give rise to the large molar absorption coefficients $(\varepsilon)$ observed. In order to make definitive assignments we utilised multiple lines of characterisation. We have prepared the analogues 2 and 3 (Fig. S3, ESI $\dagger$ ) and also exposed these samples to air to form the uranyl salts $\left[\mathrm{UO}_{2} \mathrm{X}_{4}\right]^{2-}$, which also aids our spectroscopic assignments. Comparison of the UV spectra of $\mathbf{1}$ and $\mathbf{2}$ (Fig. 1) clearly indicates that the intense band at $277 \mathrm{~nm}$ does

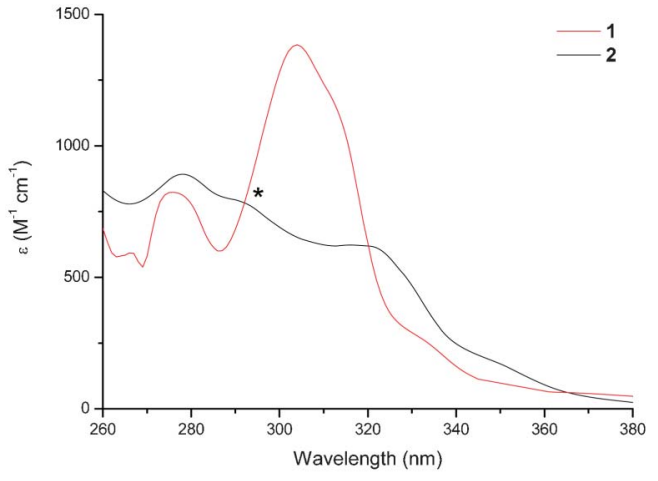

Fig. 1 UV absorption spectra of $\mathbf{1}$ (red line) and $\mathbf{2}$ (black line) in THF at ca. 1 $\mathrm{mmol}$ concentration (* indicates uranyl impurity).

not significantly shift upon halide substitution from $\mathrm{Cl}$ (1) to $\mathrm{Br}$ (2) and can therefore be assigned as an $\mathrm{f}-\mathrm{d}$ transition, probably from the ground ${ }^{3} \mathrm{H}_{4}$ state into the ${ }^{3} \mathrm{~F}_{2}$ RussellSaunders coupled state $\left(6 \mathrm{~d} \mathrm{t}_{2 \mathrm{~g}}\right.$ orbitals). ${ }^{21}$ This is Laporte allowed and therefore relatively large molar absorption coefficients would be expected.

The band at $303 \mathrm{~nm}$ exhibits a red-shift on halide substitution (to $322 \mathrm{~nm}$ in 2), which indicates that this is likely to be a CT band containing a contribution from a halide to uranium charge transfer process. In order to ascertain the presence and direction of a charge transfer band (i.e. LMCT or MLCT) we have used cyclic voltammetry (CV). The electrochemistry of $\mathbf{1}$ has been previously reported, with a reduction potential of $-2.75 \mathrm{~V}\left(\mathrm{vs} . \mathrm{Ag} / \mathrm{Ag}^{+}\right.$at $\left.298 \mathrm{~K}\right)$ and no observable oxidation wave. ${ }^{14}$ We observe identical electrochemical behaviour, and have re-examined the electrochemistry at variable temperatures as this enables the thermodynamic parameters to be extracted. Thus, a plot of the redox potential $v s$. temperature allows $\Delta S$ and $\Delta H$ to be determined. ${ }^{22} 1$ shows a well-defined temperature dependence and the thermodynamic parameters are $\Delta H=464 \mathrm{~kJ} \mathrm{~mol}^{-1}$ and $\Delta S=666 \mathrm{~J} \mathrm{~mol}^{-1}$ $\mathrm{K}^{-1}$ (Fig. S4, ESI $\dagger$ ). Entropy is measured directly in this technique, whilst there are some errors associated with the enthalpy, it should be taken as a relative measure rather than an absolute one. Nevertheless, the large enthalpy is to be anticipated as the redox potential of $-2.75 \mathrm{~V}$ suggests that $\mathbf{1}$ is difficult to reduce. We suggest that the use of temperature dependent CV may become a useful tool in studying the thermodynamics of actinide compounds. The electrochemistry of 2 shows analogous behaviour (Fig. S5, ESI $\dagger$ ), with the reduction potential of $-2.03 \mathrm{~V}$ for the reduction wave. This indicates that any charge transfer must be LMCT in character, and the decrease in the reduction potential for $\mathbf{2}$ is in accord with the bathochromic shift observed in the UV absorption spectrum. The variable temperature electrochemistry gives $\Delta H$ $=336 \mathrm{~kJ} \mathrm{~mol}^{-1}$ and $\Delta S=471 \mathrm{~J} \mathrm{~mol}^{-1} \mathrm{~K}^{-1}$, in keeping with the less negative redox potential observed in $\mathbf{1}$. Of note is that under no experimental conditions were we able to observe a $\mathrm{U}(\mathrm{IV}) / \mathrm{U}(\mathrm{v})$ oxidation in either $\mathbf{1}$ or $\mathbf{2}$; the lack of an oxidation potential has commonly been observed in previous systematic reports of $\mathrm{CV}$ investigations of $\mathrm{U}(\mathrm{IV})$ compounds with $\sigma$-donating ligands ${ }^{8 \mathrm{~h}}$ as the $\mathrm{U}(\mathrm{v})$ species formed is unstable 


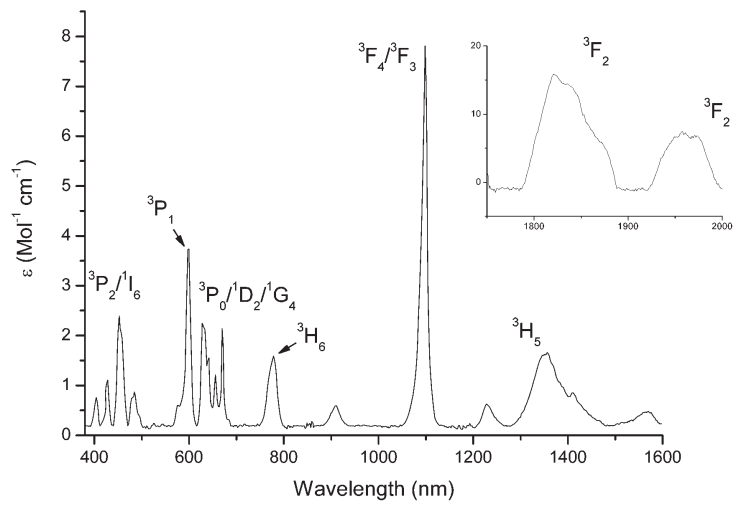

Fig. 2 Assignment of intraconfigurational $f-f$ transitions in $\mathbf{1}$ (insert shows bands in the region $1750-2000 \mathrm{~nm}$ ).

with respect to disproportionation on the $\mathrm{CV}$ timescale. Important exceptions to this observation are $\left[\mathrm{Cp}_{3} \mathrm{U}\left(\mathrm{NEt}_{2}\right)\right],{ }^{23}$ and $\left[\left(\mathrm{C}_{5} \mathrm{H}_{4} \mathrm{R}\right)_{3} \mathrm{UCl}\right]\left(\mathrm{R}=\mathrm{H}, \mathrm{Me},{ }^{t} \mathrm{Bu}, \mathrm{SiMe}_{3}\right) .{ }^{24}$ Except for the mono(amide) complex, the $\mathrm{U}(\mathrm{IV}) / \mathrm{U}(\mathrm{V})$ couple is proposed to be linked to a subsequent chemical reaction, which presumably involves disproportionation of the $\mathrm{U}(\mathrm{v})$ species. Notably the UV-vis absorption spectra of the compounds $\left[\mathrm{Et}_{4} \mathrm{~N}\right]_{2}\left[\mathrm{UCl}_{6}\right]$ and $\mathrm{UCl}_{4}$ in anhydrous THF are remarkably similar to $\mathbf{1}$ and display absorption maxima at $280 \mathrm{~nm}, 307 \mathrm{~nm}, 331 \mathrm{~nm}\left(\left[\mathrm{Et}_{4} \mathrm{~N}\right]_{2}\left[\mathrm{UCl}_{6}\right]\right)$ and 260, 290 and $334 \mathrm{~nm}$ for $\left[\mathrm{UCl}_{4}(\mathrm{THF})_{3}\right]^{25}$ (Fig. S6, ESI $\dagger$ ), suggesting that the change in symmetry does not have a noticeable effect and that a THF to uranium charge transfer band can be discounted.

The bands observed in the visible and NIR region for $\mathbf{1}$ are the formally Laporte forbidden $\mathrm{f} \rightarrow \mathrm{f}$ transitions of the $\mathrm{U}^{4+} 5 \mathrm{f}^{2}$ ion (Fig. 2). The molar absorptivity of these bands is typical for this type of actinide compound $\left(\varepsilon \approx 5-40 \mathrm{M}^{-1} \mathrm{~cm}^{-1}\right)$ and higher than observed in lanthanide(III) complexes due to the greater radial extension of the $5 \mathrm{f}$ orbitals compared to the $4 \mathrm{f}$ orbitals. The spectrum of $\mathbf{1}$ can be deconvoluted and, using previously published energy level diagrams derived from experimental data ${ }^{26}$ and computational studies (vide infra), the $\mathrm{f}-\mathrm{f}$ transitions in $\mathbf{1}$ can be fully assigned. The highest energy $\mathrm{f}-\mathrm{f}$ transition to the ${ }^{1} \mathrm{~S}_{0}$ state is likely to be buried under the more intense bands in the UV region. Interestingly, this band is significantly lowered upon solvation $\left(\mathrm{U}^{4+}{ }_{(\mathrm{g})}, 221 \mathrm{~nm}\right.$ $\left.\left(45316 \mathrm{~cm}^{-1}\right) ; \mathrm{U}^{4+}{ }_{(\mathrm{aq})}, 245 \mathrm{~nm}\left(40820 \mathrm{~cm}^{-1}\right)\right),{ }^{7,27}$ and suggests it may be sensitive to the coordination environment.

An interesting comparison can be made to the $\left[\mathrm{UCl}_{6}\right]^{2-}$ anion. Hydrogen bonding is generally sufficient to distort the geometry so that symmetry forbidden bands can be observed, albeit with molar absorption coefficients $\varepsilon=2-5 \mathrm{M}^{-1} \mathrm{~cm}^{-1} .^{28}$ We initially postulated that a lowering of the local symmetry from $O_{\mathrm{h}}$ to $C_{4 \mathrm{v}}$ in 1 would allow any symmetry-forbidden bands to be observed. Due to the air-sensitive nature of these solutions, it was difficult to accurately determine the concentration, and we anticipate that there may be a reasonable error associated with our determined $\varepsilon$ values. However, the observed colour of equimolar solutions of $\mathbf{1}$ and $\left[\mathrm{UCl}_{6}\right]^{2-}$ (Fig. S7, ESI $\dagger$ ) supports the rather surprising outcome that molar absorption coefficients of $\mathbf{1}$ are lower than $\left[\mathrm{UCl}_{6}\right]^{2-}$.
Interestingly, there appears to be little difference in the energy of the bands for both $\mathbf{1}$ and $\left[\mathrm{UCl}_{6}\right]^{2-}$, which suggests that the local symmetry is not as important as the coordination geometry and crystal field effects are not large. Whilst the uranyl was the major decomposition product in the isolation of 3 , the $\mathrm{f}-\mathrm{f}$ transitions occur in a region where this ion does not absorb. These transitions for $\mathbf{2}$ and $\mathbf{3}$ are rather similar, as seen in Fig. S3, ESI†. This is as expected if the crystal field effects are small, resulting in negligible perturbation of the $5 \mathrm{f}$ manifold.

Photoluminescence Spectroscopy. The emission spectra of the U(IV) compounds are discussed in this section. It is important to note that this is only the second example of emission spectroscopy reported for U(IV) compounds ${ }^{6}$ and the first in non-aqueous solutions. ${ }^{29}$ Due to the air sensitive nature of these solutions, it was difficult to accurately determine the concentration, so that for all photoluminescence spectroscopic measurements the solution concentrations were determined by absorbance spectra which had typical absorbance of the most intense band at 0.5 absorbance units; whilst this is generally higher than ideally required for photoluminescence measurements, the weak U(IV) emission and the difficulties associated in the handling of these challenging samples, made this unavoidable. We take the possibility of self-absorption and aggregate emission into account in the discussion of our data. Excitation into any UV absorption band of solutions of 1 in THF ( $\lambda_{\text {exc }}=260$ to $390 \mathrm{~nm}$ ) with continuous wave or pulsed UV-vis light sources produces identical emission spectra with three, featureless bands observable in the UV and visible region centred at $365 \mathrm{~nm}$, $421 \mathrm{~nm}$ and $518 \mathrm{~nm}$ (Fig. 3a). Moreover, reducing the emission monochromator slit widths (e.g. to $<0.5 \mathrm{~nm}$ ) produces identical broad emission bands, with no additional structure, this suggests that excitation into the highest energy absorption band results in excitation into vibrationally coupled states of the $5 \mathrm{f}^{1} 6 \mathrm{~d}^{1}$ configuration, which then relax to a lower energy level arising from the same electronic configuration resulting in emission at $c a .365 \mathrm{~nm}$. The two remaining lower energy transitions at 421 and $518 \mathrm{~nm}$ are likely to terminate on successively higher energy Russell-Saunders coupled states in

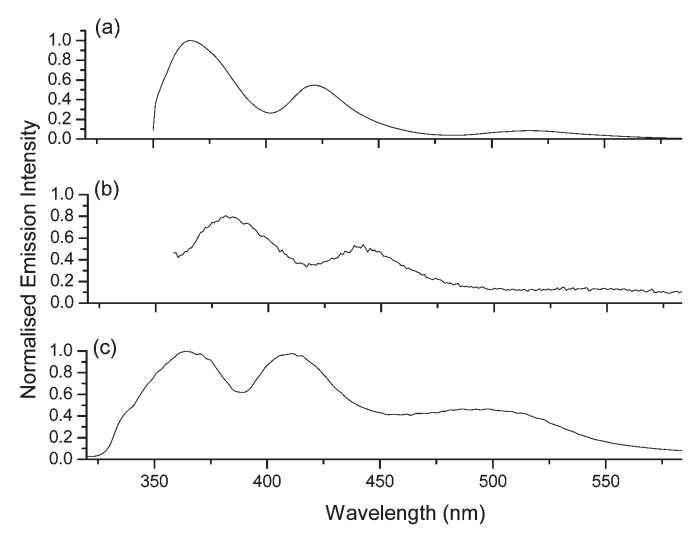

Fig. 3 (a) Emission spectrum of $\mathbf{1}$ in THF ( $\left.\lambda_{\mathrm{ex}}=303 \mathrm{~nm}\right)$; (b) emission spectrum of 2 in THF $\left(\lambda_{\text {ex }}=325 \mathrm{~nm}\right)$; (c) emission spectrum of $\left[\mathrm{UCl}_{4}(\mathrm{THF})_{3}\right]$ in THF $\left(\lambda_{\mathrm{ex}}=290\right.$ $\mathrm{nm}$ ), all measured at $298 \mathrm{~K}$ (Raman bands have been subtracted). 
the $5 \mathrm{f}^{2}$ ground state configuration. This is in agreement with the U(IV) doped solid state system U : $\mathrm{LiYF}_{4},{ }^{5 \mathrm{a}}$ although the photoluminescent spectra are considerably more resolved; an effect of increased vibrational coupling of the excited electronic states in fluid solution. The compounds 2 and 3 also exhibit broadly similar emission profiles, albeit with small blue shifts ( $c a .20 \mathrm{~nm}$ for 2, Fig. 3b). The emission spectra for $\left[\mathrm{UCl}_{6}\right]^{2-}$ (Fig. S8, ESI $\dagger$ ) and $\left[\mathrm{UCl}_{4}(\mathrm{THF})_{3}\right]$ (Fig. 3c) are comparable, as expected from the similarities in the absorption spectra. Using the assignments from the absorption spectra and CASPT2 calculations (vide infra), the bands in the emission spectra can be assigned as transitions from the $5 \mathrm{f}^{1} 6 \mathrm{~d}^{1}$ state to the ${ }^{3} \mathrm{~F}_{3}\left(\mathbf{1}, 365 \mathrm{~nm} ; 2,384 \mathrm{~nm} ;\left[\mathrm{UCl}_{6}\right]^{2-}, 364 \mathrm{~nm}\right.$; $\left.\left[\mathrm{UCl}_{4}(\mathrm{THF})_{3}\right], 365 \mathrm{~nm}\right),{ }^{1} \mathrm{G}_{4}\left(\mathbf{1}, 421 \mathrm{~nm} ; 2,442 \mathrm{~nm} ;\left[\mathrm{UCl}_{6}\right]^{2-}\right.$, $\left.424 \mathrm{~nm} ;\left[\mathrm{UCl}_{4}(\mathrm{THF})_{3}\right], 408 \mathrm{~nm}\right)$ and ${ }^{3} \mathrm{P}_{1}(1,518 \mathrm{~nm} ; 2,541 \mathrm{~nm}$; $\left.\left[\mathrm{UCl}_{6}\right]^{2-}, 510 \mathrm{~nm} ;\left[\mathrm{UCl}_{4}(\mathrm{THF})_{3}\right], 500 \mathrm{~nm}\right) 5 \mathrm{f}^{2}$ states. However as the bands are quite broad the emissions are most probably due to an envelope of energy levels; this is borne out to a certain extent by analysis of the CASPT2 calculated transitions and comparison to the assignments in earlier reports on doped systems. We were unable to measure the quantum yield for all compounds in this study as the emissions are weak, but the intensity of these emissions are comparable to the Raman bands from the solvent; the data in Fig. 3 has these bands removed, (Fig. S9, ESI $\dagger$ displays the raw data).

All excitation spectra recorded at the respective emission maxima ( $c a .365,420$ and $510 \mathrm{~nm}$ ) are wavelength independent and strongly suggest that the emission bands originate from a common excited state (Fig. S10 and S11, ESI†), which is in broad agreement with the emission lifetime data. Under the concentrations measured (absorbance units of 0.2 for the CT band at $303 \mathrm{~nm} ; c a .1 \mu \mathrm{M}$ ) there is a small Stokes shift of 10 $\mathrm{nm}$, that may be due to the comparatively high concentration. The observed emission lifetime of $\mathbf{1}$ is $\sim 4 \mathrm{~ns}$ and is independent of emission wavelength $(365 \mathrm{~nm}, 421 \mathrm{~nm}$ and $518 \mathrm{~nm}$ ) confirming that each band originates from the same emissive state. Comparable emission lifetimes are observed for 2, 3, $\left[\mathrm{UCl}_{6}\right]^{2-}$ and $\left[\mathrm{UCl}_{4}(\mathrm{THF})_{3}\right]$. We note that the lifetimes are multiexponential when reconvolution of the kinetic data is employed (Fig. S12, ESI†) giving lifetime values in the range 210 ns. Such behaviour may suggest that multiple radiative processes are occurring in fluid solution and that radiative decay may involve more than one excited state. This is possibly due to the fact that the emission bands encompass an envelope of excited state configurations, however we cannot eliminate a contribution from aggregate emission as the cause of this deviation from monoexponentiality and further studies are being conducted. Similar decay kinetics for the analogous emission bands in $\left[\mathrm{UCl}_{4}(\mathrm{THF})_{3}\right]$ and $\left[\mathrm{UCl}_{6}\right]^{2-}$ were also measured. By comparison, the emissive lifetimes of the seven resolvable $5 \mathrm{f}^{1} 6 \mathrm{~d}^{1} \rightarrow 5 \mathrm{f}^{2}$ charge transfer bands in the system $\mathrm{U}: \mathrm{LiYF}_{4}$ are $17 \mathrm{~ns}$ and for the macrocyclic complex $[\mathrm{U}(\mathrm{DO} 3 \mathrm{~A})] \mathrm{Br}(\mathrm{DO} 3 \mathrm{~A}=[4,7,10$-tris-carboxymethyl-1,4,7,10-tetraaza-cyclododec-1-yl]-acetic acid) the radiative lifetimes range 8-12 ns. This indicates that photo-induced electron transfer from the chloride ions in the complexes $\mathbf{1},\left[\mathrm{UCl}_{6}\right]^{2-}$ and $\mathrm{UCl}_{4}$ may act to quench the emission to a certain degree and/or bimolecular deactivation with labile THF solvent molecules may increase the rate of radiative decay. However, when

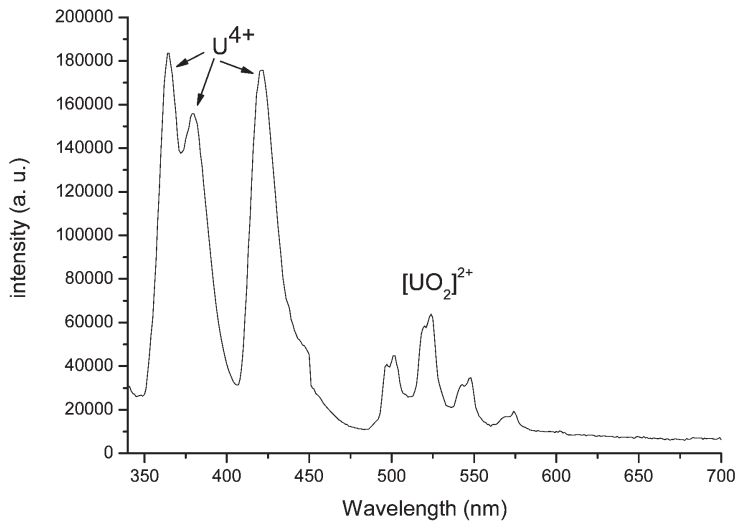

Fig. 4 Emission spectrum of $\mathbf{1}$ in THF at $77 \mathrm{~K}\left(\lambda_{\mathrm{ex}}=303 \mathrm{~nm}\right)$.

compared to the organometallic compound in the metallocene ketimide system $\left[\mathrm{Cp}_{2}{ }_{2} \mathrm{U}\left\{\mathrm{NC}(\mathrm{Ph})\left(\mathrm{CH}_{2} \mathrm{Ph}\right)\right\}_{2}\right]\left(\mathrm{Cp}^{*}=\mathrm{C}_{5} \mathrm{Me}_{5}\right)$, the lifetimes are long and easily measured using commercial instrumentation. Unfortunately, we have been unable to directly excite into the visible and near infra-red f-f U(Iv) transitions (e.g. at $c a .420,640,880$ and $980 \mathrm{~nm}$ ) and observe emission in all complexes studied, even in more concentrated solutions (millimolar rather than micromolar) using our current equipment. This is not unexpected due to the low molar absorption coefficients observed for these transitions (Fig. 2).

Low temperature $(77 \mathrm{~K})$ emission experiments were also conducted to enable better spectral resolution such that transitions to individual energy levels may be assigned. The $77 \mathrm{~K}$ emission spectra of all compounds in this study were consistently observed to be a mixture of U(IV) and a uranyl moiety, assigned on the basis of the diagnostic vibronically coupled uranyl peak centred at $524 \mathrm{~nm}$ (Fig. 4). In order to ensure that the $\mathrm{U}(\mathrm{IV})$ spectrum we observe does not come from a $\left[\mathrm{U}^{\mathrm{VI}} \mathrm{O}_{2}\right]^{2+}$ species, a solution of $\left[\mathrm{Li}(\mathrm{THF})_{4}\right]\left[\mathrm{UCl}_{5}(\mathrm{THF})\right]$ in $\mathrm{THF} /$ pyridine was exposed to air and the room temperature emission spectrum observed over time (Fig. 5). This clearly shows the decrease in intensity of the U(IV) species and an

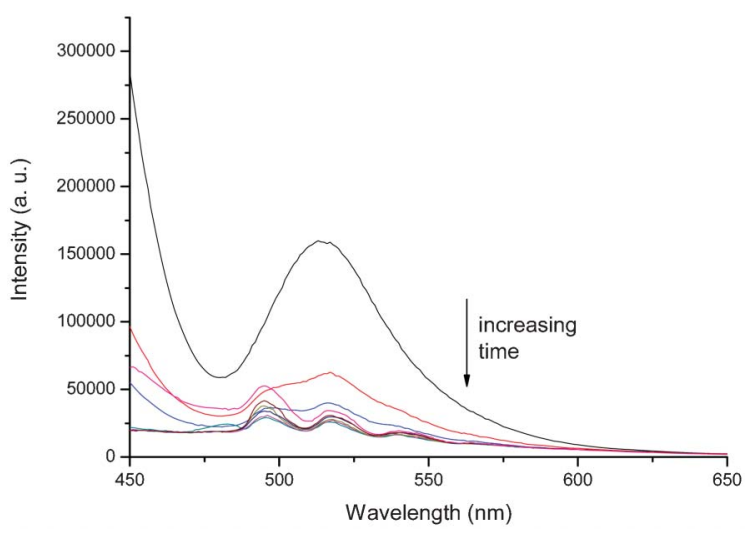

Fig. 5 Oxidation of $\mathbf{1}$ in THF/pyridine monitored by the emission band at 518 $\mathrm{nm}$ over time $\left(\lambda_{\mathrm{ex}}=303 \mathrm{~nm} ; 298 \mathrm{~K}\right)$. 
Table 1 CASPT2 calculated $5 f^{1} 6 d^{1} \rightarrow 5 f^{2}$ transitions for $\left[\mathrm{UCl}_{6}\right]^{2-}$, $\left[\mathrm{UCl} \mathrm{I}_{5}(\mathrm{THF})\right]^{-}$ and $\left[\mathrm{UCl}_{4}(\mathrm{THF})_{3}\right]$. Values in parentheses are intensities, relative to the most intense ${ }^{3} \mathrm{H}_{4}$ transition; values in bold are the experimentally determined transitions

\begin{tabular}{llll}
\hline $5 f^{2}$ State & $\lambda(\mathrm{nm})\left[\mathrm{UCl}_{6}\right]^{2-}$ & $\lambda(\mathrm{nm})\left[\mathrm{UCl}_{5}(\mathrm{THF})\right]^{-}$ & $\lambda(\mathrm{nm})\left[\mathrm{UCl}_{4}(\mathrm{THF})_{3}\right]$ \\
\hline${ }^{3} \mathrm{H}_{4}$ & $256(1)$ & $251(1)$ & $241(1)$ \\
${ }^{3} \mathrm{~F}_{2}$ & $291(0.33)$ & $290(0.29)$ & $275(0.38)$ \\
${ }^{3} \mathrm{H}_{5}$ & $304(0.14)$ & $292(0.16)$ & $284(0.17)$ \\
${ }^{3} \mathrm{~F}_{4}$ & $310(0.14)$ & $310(0.086)$ & $319(0.17)$ \\
${ }^{3} \mathrm{~F}_{3}$ & $337(0.14)$ & $334(0.14)$ & $323(0.12)$ \\
& $\mathbf{3 6 4}$ & $\mathbf{3 6 5}$ & $\mathbf{3 6 5}$ \\
${ }^{3} \mathrm{H}_{6}$ & $325(0.04)$ & $334(0.029)$ & $327(0.030)$ \\
${ }^{1} \mathrm{G}_{4}$ & $439(0.017)$ & $428(0.018)$ & $413(0.026)$ \\
& $\mathbf{4 2 4}$ & $\mathbf{4 2 1}$ & $\mathbf{4 0 8}$ \\
${ }^{1} \mathrm{D}_{2}$ & $468\left(5.3 \times 10^{-3}\right)$ & $453\left(5.0 \times 10^{-3}\right)$ & $388(0.01)$ \\
${ }^{3} \mathrm{P}_{1}$ & $600\left(2.7 \times 10^{-3}\right)$ & $554\left(3.2 \times 10^{-3}\right)$ & $494\left(5.0 \times 10^{-3}\right)$ \\
& $\mathbf{5 1 0}$ & $\mathbf{5 1 8}$ & $\mathbf{5 0 0}$
\end{tabular}

increase in the vibronically coupled $\left[\mathrm{UO}_{2}\right]^{2+}$ band. After standing for a period of time, small yellow crystals suitable for X-ray analysis were deposited in the cuvette and the structure was determined to be $[\mathrm{PyH}]_{2}\left[\mathrm{UO}_{2} \mathrm{Cl}_{6}\right]$ (Fig. S13, ESI $\dagger$ ); the structure is unremarkable, with metric parameters typical for this ion. ${ }^{30}$ This structure determination proved our hypothesis that the spectrum is due to the uranyl(vi) ion as the low temperature emission spectrum of these crystals dissolved in THF show features that are identical to that shown in Fig. 5.

\section{CASPT2 study of $\mathbf{5} f^{\mathbf{1}} \mathbf{6} \mathrm{d}^{\mathbf{1}}-\mathbf{5} f^{\mathbf{2}}$ transitions.}

State averaged CASSCF (complete-active-space self-consistentfield $)^{31}$ calculations were performed using version 7.6 of the MOLCAS code. ${ }^{32}$ Dynamic correlation was included via multiconfigurational 2nd order perturbation theory (CASPT2). ${ }^{33}$ Whilst DFT calculations show a small degree of covalency in the $\mathrm{U}-\mathrm{Cl}$ bond (vide infra), the bonding is essentially ionic and therefore the $\mathrm{Cl}$ orbitals are not included in these calculations. ${ }^{34}$ All possible $5 \mathrm{f}^{2}$ and $5 \mathrm{f}^{1} 6 \mathrm{~d}^{1}$ configurations were considered, resulting in 119 states in the absence of spin orbit coupling, which was included using the RASSI formalism. ${ }^{35}$ This resulted in a total of 231 spin-orbit coupled states. Although the reduced symmetry of the complexes considered in this study means that atomic term symbols cannot be rigorously defined, the weak ligand field experienced by the uranium ion means that those dominated by $5 \mathrm{f}^{2}$ configurations can be approximated, and these approximate term symbols are quoted here. Throughout this discussion energies and states will be given only for $\left[\mathrm{UCl}_{5}(\mathrm{THF})\right]^{-}$; for the corresponding $\left[\mathrm{UCl}_{6}\right]^{2-}$ and $\left[\mathrm{UCl}_{4}(\mathrm{THF})_{3}\right]$ data, the reader is referred to Table 1.

The CASPT2 calculations (Fig. 6) reveal that the $5 \mathrm{f}^{2}$ and $5 \mathrm{f}^{1} 6 \mathrm{~d}^{1}$ manifolds interact only very weakly in the presence of spin orbit coupling, with the exception of the high energy ${ }^{1} \mathrm{~S}_{0}$ $5 f^{2}$ state. In the absence of any $5 f^{1} 6 d^{1}$ contribution this state is calculated to lie $49500 \mathrm{~cm}^{-1}(202 \mathrm{~nm})$ above the ground state; inclusion of the $5 \mathrm{f}^{1} 6 \mathrm{~d}^{1}$ states results in significant stabilisation, to $42600 \mathrm{~cm}^{-1}(235 \mathrm{~nm})$. The extent of the mixing is revealed when the contribution of the $5 \mathrm{f}^{2}$ spin-orbit free terms

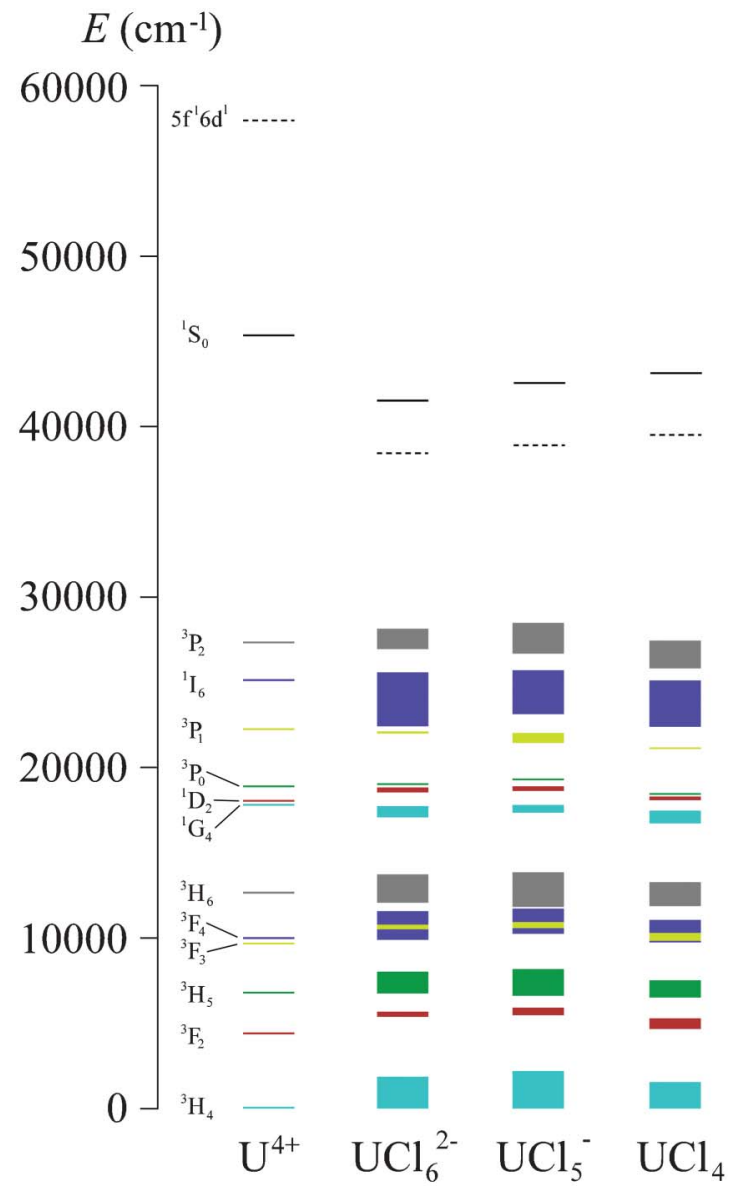

Fig. 6 Computed mean ground and excited state energy levels and assignments for $\mathrm{U}^{4+}$ in $\mathrm{H}_{2} \mathrm{O}$, $\left[\mathrm{UCl}_{6}\right]^{2-}$, $\left[\mathrm{UCl}_{5}(\mathrm{THF})\right]^{-}$and $\left[\mathrm{UCl}_{4}(\mathrm{THF})_{3}\right]$. Note a PCM solvent continuum of $\mathrm{H}_{2} \mathrm{O}$ was used in the calculations of $\mathrm{U}^{4+}$, but no explicit water molecules ligated to the $\mathrm{U}(\mathrm{IV})$ centre were included, meaning the ${ }^{1} \mathrm{~S}_{0}$ state may be artificially high in energy.

to the latter states is considered; this contribution is $24 \%$. The lowest lying $5 \mathrm{f}^{1} 6 \mathrm{~d}^{1}$ state is calculated to lie at $38600 \mathrm{~cm}^{-1}(259$ $\mathrm{nm} ; c f .277 \mathrm{~nm}$ in the experimental spectrum) and so clearly, the $5 \mathrm{f}^{1} 6 \mathrm{~d}^{1}$ manifold begins at a lower energy than the ${ }^{1} \mathrm{~S}_{0}$ state (Fig. 6). Of the other $5 \mathrm{f}^{2}$ states, the highest in energy is calculated to lie at $28500 \mathrm{~cm}^{-1}$ (351 nm) and analysis of the calculated emission spectrum strongly supports the view that the observed emissions are due to $5 \mathrm{f}^{1} 6 \mathrm{~d}^{1} \rightarrow 5 \mathrm{f}^{2}$ transitions. Furthermore, the excitation wavelength $\left(\lambda_{\mathrm{ex}}=260\right.$ to $\left.390 \mathrm{~nm}\right)$ implies that the observed transitions originate from the lower part of the $5 \mathrm{f}^{1} 6 \mathrm{~d}^{1}$ manifold, most probably the ${ }^{3} \mathrm{~F}_{2}$ state. Bearing this in mind, a subgroup of all calculated transitions was used in order to interpret the observed emission spectra. This subgroup consisted only of transitions originating from states in the $5 \mathrm{f}^{1} 6 \mathrm{~d}^{1}$ manifold lying $\leqslant 44400 \mathrm{~cm}^{-1}(\geqslant 225 \mathrm{~nm})$ above the ground state (i.e. just above the calculated position of the $5 \mathrm{f}^{2}{ }^{2} \mathrm{~S}_{0}$ state) and having an oscillator strength $f \geqslant 10^{-5}$. This reduced the number of considered transitions from 24627 to 915 . The analysis reveals that the effect of the ligand environment is to significantly broaden all transitions, and so 
the positions quoted here are obtained as the peak value of all transitions to a given $5 \mathrm{f}^{2}$ state combined.

An intense peak is calculated at $251 \mathrm{~nm}$ and corresponds to a transition into the ${ }^{3} \mathrm{H}_{4}$ ground-state of the $5 \mathrm{f}^{2}$ manifold. Two strong peaks are calculated at 290 and $292 \mathrm{~nm}$ and correspond to transitions into the ${ }^{3} \mathrm{~F}_{2}$ and ${ }^{3} \mathrm{H}_{5}$ states, respectively. An intense peak is calculated at $334 \mathrm{~nm}$ and is primarily due to a transition into the ${ }^{3} \mathrm{~F}_{3}$ state, with a small component corresponding to a transition into ${ }^{3} \mathrm{H}_{6}$. Since there are no other transitions calculated to be in this energy range, we assign the experimentally observed transition at $365 \mathrm{~nm}$ as being into the ${ }^{3} F_{3}$ state. A weaker transition into the ${ }^{1} G_{4}$ state is calculated at $428 \mathrm{~nm}$ and is assigned to the observed transition at $421 \mathrm{~nm}$. There is also a very weak contribution to this peak from a transition into the ${ }^{1} \mathrm{D}_{2}$ state at $453 \mathrm{~nm}$. At longer wavelengths, transitions become very broad and weak; the strongest transition is into the ${ }^{3} \mathrm{P}_{1}$ state at $554 \mathrm{~nm}$, which we assign to the observed transition at $518 \mathrm{~nm}$. No significant peaks are calculated at longer wavelengths.

On the basis of the experimental and computational results presented herein, we propose that excitation into a band of charge transfer and $6 \mathrm{~d}$ orbital character leads to electron transfer into the f-orbital manifold. Final evidence that the emission arises from the f-orbitals comes from the observation that no photoluminescence spectra are obtained when $\left[\mathrm{ThCl}_{4}(\mathrm{DME})_{2}\right]^{36}$ is examined. ${ }^{37}$ The f-orbitals on the closed shell Th(IV) ion are known to be much higher in energy and generally not involved in bonding. Notably, the absorption, excitation and emission spectra for all the chloride complexes studied are similar, which supports the argument that in fluid solution at least, the geometry and local symmetry at the U(IV) ion have a minor effect on the optical properties of the complex. However, the CASPT2 data indicate that the energies and the relative ordering of the Russell-Saunders coupled levels derived from the $5 \mathrm{f}^{2}$ configuration show a degree of sensitivity to site symmetry and crystal field effects as might be anticipated for this $5 \mathrm{f}$ ion. The observation that emission spectra of $\mathrm{U}(\mathrm{IV})$ can be measured in the presence of $\left[\mathrm{U}^{\mathrm{VI}} \mathrm{O}_{2}\right]^{2+}$ may be of substantial benefit in environmental applications. Importantly, the relatively large quantum yield of uranyl(vi) emission in a frozen glass means that trace quantities can be detected alongside U(IV); the U(IV) emission can be removed by applying a time gate and time delay (e.g. $0.05 \mu \mathrm{s})$.

\section{Computational study of the bonding in 1.}

In order to gain further insight into the electronic structure of these compounds, especially degree of covalency in the $\mathrm{U}-\mathrm{Cl}$ bonds, we turn to density functional theory (DFT), which is increasingly being utilised in this field. ${ }^{38}$ Geometry optimisation of triplet $\left[\mathrm{UCl}_{5}(\mathrm{THF})\right]^{-}$at a number of levels of theory results in a distorted octahedral geometry with $C_{2}$ symmetry. A comparison between the calculated and experimentally determined bond lengths and angles are reported in Table S1, (ESI $\dagger$ ). The DFT geometries generally reproduce the solid-state geometry, with one short $\mathrm{U}-\mathrm{Cl}$ bond and $\mathrm{Cl}-\mathrm{U}-\mathrm{O}$ angle of less than $90^{\circ}$, but overestimate the $\mathrm{U}-\mathrm{O}$ bond length. In addition, comparison of the experimentally determined U-Cl stretch in the Raman spectrum $\left(305 \mathrm{~cm}^{-1}\right)$ against BP86 $\left(289.8 \mathrm{~cm}^{-1}\right)$

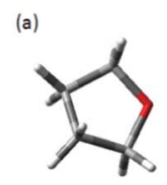

(c)

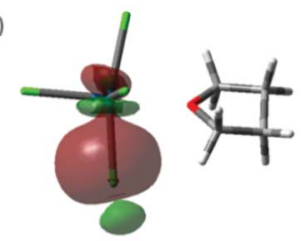

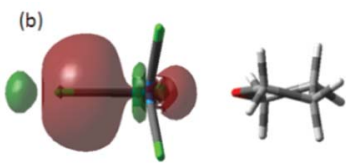

(d)

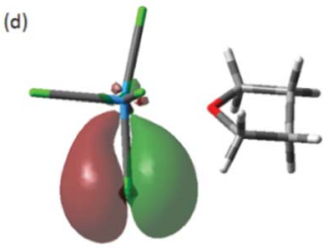

Fig. 7 (a) DFT spin density and isosurfaces for $\sigma$-natural bonding orbitals in (b) $\mathrm{U}-\mathrm{Cl}_{\mathrm{ax}}$ and (c) $\mathrm{U}-\mathrm{Cl}_{\text {eq }}$ and (d) $\pi$-natural bonding orbitals in orbitals in $\mathrm{U}-\mathrm{Cl}_{\text {eq }}$ of the anionic component of $\mathbf{1}$.

and B3LYP (294.5 $\left.\mathrm{cm}^{-1}\right)$ (Fig. S14-S16, ESI†) confirms the suitability of these methods to describe the bonding in $\mathbf{1}$.

With this in mind, comparison of $\alpha$ - and $\beta$-spin NBOs demonstrates that the two unpaired electrons in the triplet state reside in orthogonal f-orbitals on $\mathrm{U}$, thus giving rise to a highly localised distribution of spin density (Fig. 7a). NBO analysis leads to an electron configuration on $\mathrm{U}$ of [cor$\mathrm{e}] 7 \mathrm{~s}^{0.27} 5 \mathrm{f}^{3.04} 6 \mathrm{~d}^{1.68} 7 \mathrm{p}^{0.50}$, and an overall atomic charge on $U$ of -0.033 . Charges on $\mathrm{Cl}$ vary slightly between -0.244 and -0.230 , and the overall charge on THF is +0.202 . Thus, NBO analysis indicates significant charge transfer from THF to $\mathrm{U}$, and much smaller atomic charges than the formal U(IV) assignment would suggest. One or more natural bonding orbitals are found between $\mathrm{U}$ and each $\mathrm{Cl}$, and within the THF unit, but no such overlap is located between $\mathrm{U}$ and $\mathrm{O}$. A single $\mathrm{NBO}$ is located between $\mathrm{U}$ and the axial chloride, weighted heavily $(83 \%)$ in favour of $\mathrm{Cl}$ and involving both $\mathrm{s}^{-}$and p-orbitals on $\mathrm{Cl}$ interacting with s-, $\mathrm{p}-$, d- and f-orbitals on $\mathrm{U}$ (Table 2 and Fig. 7b). Orbitals with similar make-up are found between $\mathrm{U}$ and all four equatorial chlorides (Fig. 7c), but here a second set of orbitals with $\pi$-symmetry that consist of $\mathrm{Cl}$ p-orbitals donating into $\mathrm{U}$ d- and f-orbitals (Fig. 7d) are also found.

NBO analysis proceeds by first defining a Lewis structure that best describes the molecule, and then reporting deviations from this in terms of donor-acceptor interactions between formally occupied and vacant NBOs. This 2 nd-order perturbation theory analysis indicates significant overlap between $\mathrm{U}$ and $\mathrm{O}$, despite the lack of a formal orbital for this interaction. This consists of donation from a p-type lone pair on $\mathrm{O}$ into a mixture of $\mathrm{d}$ - and f-orbitals on $\mathrm{U}$, whose bond

Table 2 NBO analysis of symmetry unique $\mathrm{U}-\mathrm{Cl}$ bonds (\%)

\begin{tabular}{llll}
\hline & $\mathrm{U} / \mathrm{Cl}$ & $\mathrm{U}$ s / p / d / f & $\mathrm{Cl} \mathrm{s} \mathrm{/} \mathrm{p}$ \\
\hline $\mathrm{U}-\mathrm{Cl}_{\mathrm{ax}}$ & $16.9 / 83.1$ & $20 / 26 / 41 / 14$ & $54 / 46$ \\
$\mathrm{U}-\mathrm{Cl}_{\text {eq }}$ & $17.5 / 82.5$ & $15 / 17 / 35 / 32$ & $52 / 48$ \\
$\mathrm{U}-\mathrm{Cl}_{\text {eq }}$ & $10.6 / 89.4$ & $0 / 10 / 47 / 43$ & $1 / 99$ \\
$\mathrm{U}-\mathrm{Cl}_{\text {eq }}$ & $17.5 / 82.5$ & $16 / 17 / 35 / 32$ & $52 / 48$ \\
$\mathrm{U}-\mathrm{Cl}_{\text {eq }}$ & $10.8 / 89.2$ & $0 / 10 / 47 / 43$ & $1 / 99$
\end{tabular}



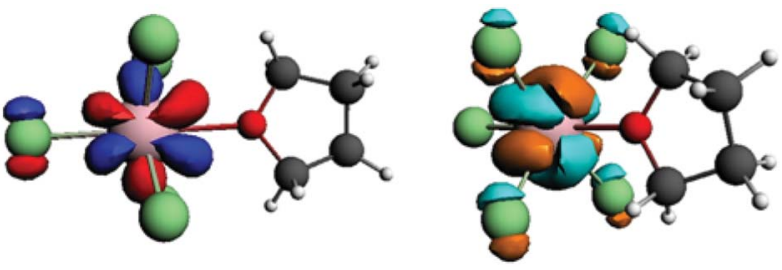

Fig. $8 \mathrm{HOMO}$ and LUMO $\alpha$-spin orbitals of $\mathbf{1}$ at the BP86 level.

energy is estimated at $49.6 \mathrm{kcal} \mathrm{mol}^{-1}$. This perturbation analysis also identifies numerous but weak donor-acceptor interactions from chloride lone pairs into formally empty dand f-orbitals on $\mathrm{U}$. These are present for all five chlorides, but their sum is noticeably larger for $\mathrm{U}-\mathrm{Cl}_{\mathrm{ax}}\left(55 \mathrm{kcal} \mathrm{mol}^{-1}\right)$ than the four equatorial chlorides (39-43 $\mathrm{kcal} \mathrm{mol}^{-1}$ ).

The HOMO consists of an f-orbital localised on the uranium centre with an antibonding contribution to the axial chloride, whilst the LUMO is a different f-orbital with an antibonding contribution to the equatorial chlorides (Fig. 8). The HOMOLUMO gap of the $\alpha$-spin is calculated to be $3.83 \mathrm{eV}$ $\left(30891 \mathrm{~cm}^{-1}\right.$ ); the corresponding gap for the $\beta$-spin is 3.41 eV $\left(39572 \mathrm{~cm}^{-1}\right)$.

\section{Atoms in molecules description}

Atoms in molecules (AIM) analysis concentrates on the topology of the electron density, and gives complementary information to that from NBO. It has begun to be utilised for actinide compounds. ${ }^{39}$ AIM analysis looks for bond critical points (BCP) between two atoms, and the chemical bonding can be characterised by the properties of these BCPs. Table 3 reports properties evaluated at bond critical points for $\mathrm{U}-\mathrm{X}$ bonds in a series of compounds, and for comparison $\mathrm{ThCl}_{4}$ and $\mathrm{LaCl}_{3}$. For 1, $\rho$ and $\nabla^{2} \rho$ suggest that these bonds are predominantly ionic. Variations in $\rho$ within symmetry-unique $\mathrm{U}-\mathrm{Cl}$ bonds are small, but more significant changes are apparent $\operatorname{in} \nabla^{2} \rho$ and $\varepsilon$ between axial and equatorial bonds. This reflects the significant $\pi$-character of the latter, which reduces the overall curvature but increases the asymmetry of the density at the BCP, but by symmetry, cannot directly affect $\rho$. However, energy density and bond order do not show the expected increase in strength of the equatorial bonds relative to the axial one, perhaps reflecting the importance of the greater second-order interactions in the latter. $\rho$ in the $\mathrm{U}-\mathrm{O}$ bond is significantly less than in all $\mathrm{U}-\mathrm{Cl}$ bonds. Further evidence for the relative weakness of this bond comes from the zero value of $H$, indicating a balance of kinetic and potential energies, and the low value of the integrated bond order; this supports the experimental observation of the lability of the coordinated THF. AIM also defines atomic charge by numerical integration of the electron density within each atomic basin: values calculated in this way are significantly different to those from NBO and suggest much greater ionicity. $U$ is found to have an overall charge of +2.26 , and chlorides vary -0.66 to -0.67 . THF is very close to neutral (overall charge of $+0.04)$.

\section{Conclusions}

In conclusion, we have shown that simple U(IV) coordination compounds are emissive at room temperature and these transitions can be assigned on the basis of experimental and computational assignments of the absorption spectrum. Notably for the first time the $\mathrm{f}-\mathrm{f}$ transitions in the electronic absorption and emission spectra can be unambiguously assigned via a CASSCF study. The emission spectra can be explained by excitation into a band of charge transfer and d-orbital character followed by rather inefficient electron transfer to the 5 f-orbitals. The lifetimes for these compounds are all in the range of 2-10 ns and multiexponential, hinting at complex deactivation and/or quenching processes. Interestingly the emission for U(IV) can be observed in the presence of $\mathrm{U}(\mathrm{VI})$, which may be of significant interest in environmental applications. Finally a comprehensive computational investigation of the bonding in $\left[\mathrm{Li}(\mathrm{THF})_{4}\right]\left[\mathrm{UCl}_{5}(\mathrm{THF})\right]$ (1) has shown that although mainly ionic, there is a contribution to the $\mathrm{U}-\mathrm{Cl}$ bond from the $5 \mathrm{f}$ and $6 \mathrm{~d}$ orbitals of up to $17 \%$. A $\pi$-interaction of mainly $U 5 \mathrm{f}$ and $6 \mathrm{~d}$ character and $\mathrm{Cl}$ p orbital has been observed. An AIM analysis of the bonding confirms the presence of this interaction.

\section{Experimental details}

\section{General methods}

Caution! Natural uranium was used during the course of these experiments. As well as the radiological hazards, uranium is a toxic metal and care should be taken with all manipulations.

Table 3 Bond critical point properties for selected compounds (values in au)

\begin{tabular}{|c|c|c|c|c|c|c|c|}
\hline Compound & & $\rho$ & $\nabla^{2} \rho$ & $\varepsilon$ & $H$ & Bond Order & Ref. \\
\hline \multirow[t]{4}{*}{1} & $\mathrm{U}-\mathrm{Cl}_{\mathrm{ax}}$ & 0.072 & +0.165 & 0.004 & -0.019 & 0.78 & \multirow[t]{4}{*}{ this work } \\
\hline & $\mathrm{U}-\mathrm{Cl}_{\mathrm{eq}}$ & 0.070 & +0.142 & 0.090 & -0.017 & 0.75 & \\
\hline & $\mathrm{U}-\mathrm{Cl}_{\mathrm{eq}}^{-1}$ & 0.071 & +0.143 & 0.096 & -0.018 & 0.76 & \\
\hline & $\mathrm{U}-\mathrm{O}$ & 0.046 & +0.132 & 0.132 & 0.000 & 0.31 & \\
\hline $\mathrm{Cp}_{4} \mathrm{U}$ & $\mathrm{U}-\mathrm{C}$ & 0.034 & +0.089 & 2.11 & -0.001 & n.r. & $39 \mathrm{a}$ \\
\hline $\mathrm{Cp}_{3} \mathrm{U}$ & $\mathrm{U}-\mathrm{C}$ & 0.040 & +0.115 & 1.31 & -0.003 & n.r. & $39 a$ \\
\hline $\mathrm{ThCl}_{4}$ & $\mathrm{Th}-\mathrm{Cl}$ & 0.081 & +0.157 & 0.011 & -0.024 & n.r. & $39 \mathrm{a}$ \\
\hline $\mathrm{LaCl}_{3}$ & $\mathrm{La}-\mathrm{Cl}$ & 0.066 & +0.159 & 0.009 & -0.011 & n.r. & $39 \mathrm{a}$ \\
\hline$\left[(\right.$ Tren $\left.) \mathrm{U}-\mathrm{RuCp}(\mathrm{CO})_{2}\right]$ & U-Ru & 0.0425 & +0.0605 & n.r. & -0.008 & n.r. & 39d \\
\hline
\end{tabular}


Experiments using uranium materials were carried out using preset radiological safety precautions in accordance with the local rules of The University of Manchester or Trinity College Dublin.

All manipulations were carried out using standard Schlenk and glove box techniques under an atmosphere of high purity argon. ${ }^{1} \mathrm{H}$ and ${ }^{7} \mathrm{Li}$ NMR spectra were recorded on a Bruker AV400 spectrometer operating at $400.23 \mathrm{MHz}$ and $155.54 \mathrm{MHz}$, respectively, and were referenced to the residual ${ }^{1} \mathrm{H}$ resonances of the solvent used or external LiCl. IR spectra were recorded on a Perkin Elmer Spectrum One spectrometer with attenuated total reflectance (ATR) accessory. Raman spectra were obtained using $785 \mathrm{~nm}$ excitation on a Renishaw 1000 micro-Raman system in sealed capillaries. Thermal scans of magnetization in a $100 \mathrm{mT}$ field from 4-300 K were carried out using a 5T Quantum Design MPMS XL SQUID magnetometer. Powdered samples were mounted in gel caps, which have a temperature-independent diamagnetic susceptibility, in a glove box and the gel caps were placed in sample straws for the measurement. Diamagnetic corrections were made using Pascal's constants. ${ }^{40}$ Multiple measurements were taken to ensure reproducibility. Electrochemical measurements were undertaken with an AUTOLAB PGSTAT12 potentiostat/galvanostat using a platinum disc electrode with a reaction surface of $1 \mathrm{~mm}^{2}$ as working electrode. A platinum rod electrode (together with internal referencing versus $\left[\mathrm{Cp}_{2} \mathrm{Fe}\right]^{0 /+}$ ) was used as a reference electrode and a platinum knob electrode as auxiliary electrode. All measurements took place in a glove box under an atmosphere of high purity nitrogen, $\left[{ }^{n} \mathrm{Bu}_{4} \mathrm{~N}\right]\left[\mathrm{BPh}_{4}\right]$ (0.1 M) was used as electrolyte. X-ray crystallography was measured on a Rikagu Saturn diffractometer. The structures were solved by direct methods and refined on $F^{2}$ by full matrix least squares (SHELX97) ${ }^{41}$ using all unique data. Crystal data, details of data collections and refinement are given in Table S2, ESI†. UV-vis/NIR measurements were made on either a Perkin Elmer Lambda 1050 spectrometer or a double-beam Cary Varian 500 scan UV-vis-NIR spectrophotometer over the range 300-1300 nm using fused silica cells with a path length of $1 \mathrm{~cm}$. Steady-state emission spectra were recorded in Young's tap appended quartz cuvettes on an Edinburgh Instrument FP920 Phosphorescence Lifetime Spectrometer equipped with a 5 watt microsecond pulsed xenon flashlamp (with single $300 \mathrm{~mm}$ focal length excitation and emission monochromators in Czerny Turner configuration) and a red sensitive photomultiplier in peltier (air cooled) housing (Hamamatsu R928P) or on a Horiba-Jobin-Yvon Fluorolog-3 spectrometer. Lifetime data were recorded following $375 \mathrm{~nm}$ and $405 \mathrm{~nm}$ excitation with an EPL 375 and EPL 405 picosecond pulsed diode laser (Edinburgh Instruments), using time correlated single photon counting (PCS900 plug-in PC card for fast photon counting). Lifetimes were obtained by tail fit on the data obtained or by a reconvolution fit using a solution of Ludox ${ }^{\mathbb{B}}$ in water as the scatterer, and quality of fit judged by minimization of reduced chi-squared and residuals squared.

Uranium stocks were obtained from the Centre for Radiochemistry Research (CRR) isotopes store at The University of Manchester or TCD's stocks. THF was distilled over potassium whilst $\mathrm{d}_{5}$-pyridine was dried over $\mathrm{Na}$, distilled and degassed immediately prior to use. Spectroscopic mea- surements used spectroscopic grade solvents which were purchased from commercial sources and dried over potassium or potassium/benzophenone, molecular sieves and thoroughly degassed before use. $\left[\mathrm{UCl}_{4}(\mathrm{THF})_{3}\right]^{42}$ and $\left[\mathrm{Et}_{4} \mathrm{~N}\right]_{2}\left[\mathrm{UCl}_{6}\right]^{43}$ were made via the literature procedures whilst all other reagents were obtained from commercial sources. LiCl was dried by refluxing in freshly distilled $\mathrm{SOCl}_{2}$ overnight, washing with copious $\mathrm{CH}_{2} \mathrm{Cl}_{2}$ and finally drying under vacuum. $\mathrm{Me}_{3} \mathrm{SiX}(\mathrm{X}=$ $\mathrm{Br}, \mathrm{I})$ was dried over $4 \AA$ molecular sieves and freeze-pumpthaw degassed immediately prior to use. Attempts at obtaining elemental analysis were consistently low in $\mathrm{C}, \mathrm{H}$ and $\mathrm{O}$, due to the lability of the solvated THF.

Preparation of $\left[\mathrm{Li}(\mathrm{THF})_{4}\right]\left[\mathrm{UCl}_{5}(\mathrm{THF})\right]$, 1. To a suspension of LiCl (11 mg, $0.26 \mathrm{mmol})$ in THF $\left(10 \mathrm{~cm}^{3}\right)$ was added a solution of $\mathrm{UCl}_{4}(100 \mathrm{mg}, 0.26 \mathrm{mmol})$ in THF $\left(10 \mathrm{~cm}^{3}\right)$ and this was stirred for $24 \mathrm{~h}$. The resulting green solution was filtered and the solvent reduced in volume. Placement at $-30{ }^{\circ} \mathrm{C}$ overnight yielded pale green crystals suitable for X-ray diffraction (150 mg, 0.19 mmol, 74\%). MPt: $145-148{ }^{\circ} \mathrm{C}$; Raman $\left(\mathrm{cm}^{-1}\right): 1185$, 1138, 1027, 997, $v$ (THF) 305, $v(\mathrm{U}-\mathrm{Cl})$; UV-vis-NIR $\left(\varepsilon\left(\mathrm{mol} \mathrm{dm}^{-3}\right.\right.$ $\mathrm{cm}^{-1}$ ): (THF, $\left.0.36 \mathrm{mmol}\right) 277$ (832), 303 (1384), 331 (258), (THF, $\sim 3.6 \mathrm{mmol}) 404$ (0.76), 428 (1.11), 452 (2.39), 484 (0.87), 599 (3.72), 627 (2.25), 655 (1.21), 667 (2.14), 778 (1.59), 909 (0.59), 1098 (7.81), 1227 (0.62), 1356 (1.60), 1571 (4.80), 1843 (15.83), 1970 (7.14) nm. $\delta_{\mathrm{Li}}$ (THF, $\left.298 \mathrm{~K}\right):-2.64 \mathrm{ppm}$.

Preparation of $\left[\mathrm{Li}(\mathrm{THF})_{4}\right]\left[\mathrm{UBr}_{5}(\mathrm{THF})\right]$, 2. To a solution of $\mathbf{1}$ (50 mg, $0.064 \mathrm{mmol})$ in THF $\left(5 \mathrm{~cm}^{3}\right)$ was added $\mathrm{Me}_{3} \mathrm{SiBr}$ in excess. The solution was stirred for $24 \mathrm{~h}$ and the solvent removed in vacuo. Dissolution in THF and placement at -30 ${ }^{\circ} \mathrm{C}$ overnight yielded dark green powder (42 mg, $0.042 \mathrm{mmol}$, 66\%) UV-vis-NIR $\left(\varepsilon\left(\mathrm{mol} \mathrm{dm}{ }^{-3} \mathrm{~cm}^{-1}\right)\right.$ : (THF, $\left.0.36 \mathrm{mmol}\right): 277$ (889), 325 (617), 350 (170), 433 (0.22), 464 (1.05), 483 (0.37), 554 (0.11), 614 (0.98), 632 (1.05), 664 (0.31), 670 (0.56), 795 (0.36) nm; $\delta_{\mathrm{Li}}(\mathrm{THF}, 298 \mathrm{~K}):-0.97 \mathrm{ppm}$.

Preparation of $\left[\mathrm{Li}(\mathrm{THF})_{4}\right]\left[\mathrm{UI}_{5}(\mathrm{THF})\right], \mathbf{3}$. To a solution of $\mathbf{1}(50$ $\mathrm{mg}, 0.064 \mathrm{mmol})$ in THF $\left(5 \mathrm{~cm}^{3}\right)$ was added $\mathrm{Me}_{3} \mathrm{SiI}$ in excess. The solution was stirred for $24 \mathrm{~h}$ to give a pale yellow solution. The solvent was removed in vacuo and dissolution in THF followed by placement at $-30{ }^{\circ} \mathrm{C}$ overnight yielded a yellow powder that contained 3 and $[\mathrm{Li}(\text { solv })]_{2}\left[\mathrm{UO}_{2} \mathrm{I}_{4}\right]$ which could not be separated. Spectroscopic data were obtained on this mixture. UV-vis: 252, 295, 365, 597, 626, 653, 669, $776 \mathrm{~nm}$; Emission spectrum (THF, 298 K): 354, 412, 508, nm.

\section{Computational details}

DFT geometry optimisation was performed on a single molecule of $\left[\mathrm{UCl}_{5}(\mathrm{THF})\right]^{-}$, extracted from the crystal structure, at the unrestricted BP86/def2-TZVP ${ }^{44,45}$ level using Turbomole ${ }^{46}$ within $\mathrm{C}_{2}$ symmetry. Scalar relativistic effects in uranium were included through use of effective core potentials, as defined for this basis set. Spin contamination was not significant, with values of $S^{2}$ within $1 \%$ of the anticipated value of 2.00 . Further single-point DFT calculations were performed in Gaussian $09^{47}$ using the BP86 and B3LYP ${ }^{48}$ functionals. The $(27 \mathrm{~s} 24 \mathrm{p} 18 \mathrm{~d} 14 \mathrm{f} 6$ $(\mathrm{g}) /[\mathrm{ss} 7 \mathrm{p} 5 \mathrm{~d} 3 \mathrm{f} 1 \mathrm{~g}]$ all-electron ANO-RCC basis sets of DZP quality were used for uranium, ${ }^{49}$ with $6-31+\mathrm{G}(\mathrm{d}, \mathrm{p})$ on $\mathrm{C}, \mathrm{O}, \mathrm{H}$ and $\mathrm{Cl}^{50}$ Scalar relativistic effects were included via the secondorder Douglas-Kroll-Hess Hamiltonian. ${ }^{51}$ Natural bond orbital (NBO) analysis ${ }^{52}$ was performed using Gaussian09; Atoms-in- 
Molecules (AIM) analysis used AIMAll. ${ }^{53}$ Topological analysis of the electronic density $(\rho)$ is based upon those points where the gradient of the density, $\nabla \rho$, vanishes. ${ }^{54}$ In this work we consider points where one curvature (in the inter-nuclear direction) is positive and two (perpendicular to the bond direction) are negative, termed $(3,-1)$ or bond critical points. Properties evaluated at such points characterise the bonding interactions present. The second derivative of $\rho$ or Laplacian, $\nabla^{2} \rho$, and the bond ellipticity, the ratio of the two negative curvatures, are reported, as is the local energy density, $H$, defined as the sum of the kinetic and potential energy densities. An electron density $(\rho)$ of 0.2 a.u. or greater typically signifies a covalent bond and less than 0.1 a.u. indicates closed shell (ionic, Van der Waals etc.). The Laplacian of this function $\left(\nabla^{2} \rho\right)$ is typically significantly negative for covalent bonding and positive for closed shell interactions. The ellipticity, $\varepsilon$, measures the shape of the electron density distribution in a plane through the BCP and thus determines the degree of cylindrical symmetry in a bond. $H$ is the total energy density (kinetic + potential energy) and is typically negative for covalent bonds. This reveals whether accumulation of electronic density is stabilising $(E<0)$ or destabilising $(E>0)$. Integrated properties of atoms were checked for numerical accuracy via the basin integral of the Laplacian, which should vanish for properly defined atomic basins (all values $10^{-4}$ or less), and also by comparison of the sum of all atomic integrals with directly calculated molecular values. Integration of the overlap matrix over atomic basins can be used to derive covalent bond order, as set out by Angyan et $a .^{55}$ State averaged CASSCF (complete-active-space selfconsistent-field $)^{56}$ calculations were performed using version 7.6 of the MOLCAS code. ${ }^{57}$ Calculations were performed using the all-electron ANO-RCC basis set, ${ }^{58}$ of polarised triple-zeta quality, and scalar relativistic effects were included via the Douglas-Kroll-Hess Hamiltonian. ${ }^{59}$ In these calculations, the two open shell uranium electrons were explicitly correlated in an active space of thirteen orbitals, comprising the $5 \mathrm{f}, 6 \mathrm{~d}$ and $7 \mathrm{~s}$ uranium orbitals. Dynamic correlation was included via multiconfigurational 2nd order perturbation theory (CASPT2). ${ }^{33} \mathrm{~A}$ Polarisable Continuum Model was utilised for U(IV).

\section{Acknowledgements}

We thank TCD (RJB and EH) and the EPSRC Career Acceleration Fellowship Scheme (LSN, ANS, AK) for funding this work. JAP and AK are grateful to UK National Service for Computational Chemistry Software. We also thank Dr Venkatesan and Prof. J. M. D. Coey (School of Physics, TCD) for SQUID measurements and Prof. John M. Kelly (TCD) for useful discussions. COST Action CM1006 is also gratefully acknowledged.

\section{Notes and references}

1 (a) J.-C. G. Bünzli, Chem. Rev., 2010, 110, 2729; (b) K. N. Allen and B. Imperiali, Curr. Opin. Chem. Biol., 2010, 14, 247; (c) E. G. Moore, A. P. S. Samuel and K. N. Raymond, Acc. Chem. Res., 2009, 42, 542; (d) C. M. G. dos Santos, A.
J. Harte, S. J. Quinn and T. Gunnlaugsson, Coord. Chem. Rev., 2008, 252, 2512; (e) J.-C. G. Bünzli and S. V. Eliseeva, J. Rare Earths, 2010, 28, 824; (f) J. Rocha, L. D. Carlos, F. A. Almeida Paz and D. Ananias, Chem. Soc. Rev., 2011, 40, 926; (g) M. D. Ward, Coord. Chem. Rev., 2010, 254, 2634; (h) L. S. Natrajan, Curr. Inorg. Chem., 2011, 1, 61; (i) S. Faulkner, L. S. Natrajan, W. S. Perry and D. Sykes, Dalton Trans., 2009, 3890.

2 (a) L. S. Natrajan, Coord. Chem. Rev., 2012, 256, 1583; (b) I. Billard and G. Geipel, in Springer Series on Fluorescence, ed. U. Resch-Genger, Springer Berlin Heidelberg, 2008, vol. 5, pp. 465-492; (c) H. D. Burrows and M. D. G. Miguel, $A d v$. Colloid Interface Sci., 2001, 89-90, 485; (d) C. P. Baird and T. J. Kemp, in Progress in Reaction Kinetics, 1997, vol. 22, p. 87; (e) R. G. Denning, J. Phys. Chem. A, 2007, 111, 4125.

3 M. P. Redmond, S. M. Cornet, S. D. Woodall, D. Whittaker, D. Collison, M. Helliwell and L. S. Natrajan, Dalton Trans., 2011, 40, 3914.

4 (a) G. Geipel, Coord. Chem. Rev., 2006, 250, 844; (b) G. Liu and J. V. Beitz, in The Chemistry of the Actinide and Transactinide Elements, ed. L. R. Morss, N. M. Edelstein and J. Fuger, Springer, Dordrecht, The Netherlands, 2010; (c) D. Girnt, P. W. Roesky, A. Geist, C. M. Ruff, P. J. Panak and M. A. Denecke, Inorg. Chem., 2010, 49, 9627.

5 (a) S. V. Godbole, A. G. Page, Sangeeta, S. C. Sabharwal, J. Y. Gesland and M. D. Sastry, J. Lumin., 2003, 93, 213; (b) S. Hubert, E. Simoni, M. Louis, W. T. Zhang and J. Y. Gestland, J. Lumin., 1994, 60, 245; (c) M. Genet, P. Delamoye, N. Edelstein and J. Conway, J. Chem. Phys., 1977, 67, 1620; (d) E. Simoni, S. Hubert and M. Genet, J. Phys., 1988, 49, 1425; C. Khan Malek, J. C. Krupa, P. Delamoye and M. Genet, J. Phys., 1986, 47, 1763; (e) C. D. Flint and P. A. Tanner, Mol. Phys., 1984, 53, 429; C. Khan Mallek and J. C. Krupa, J. Chem. Phys., 1986, 84, 6584; (f) B. Ordejón, V. Vallet, J.-P. Flament, L. Seijoa and Z. Barandiarána, J. Lumin., 2007, 126, 779; $(g)$ B. Ordejón, M. Karbowiak, L. Seijo and Z. Z. Barandiarána, J. Chem. Phys., 2006, 125, 074511.

6 (a) A. Kirishima, T. Kimura, O. Tochiyama and Z. Yoshida, Chem. Commun., 2003, 910; (b) A. Kirishima, T. Kimura, R. Nagaishi and O. Tochiyama, Radiochim. Acta, 2004, 92, 705.

7 C. Danilo, V. Vallet, J.-P. Flament and U. Wahlgren, Phys. Chem. Chem. Phys., 2010, 12, 1116.

8 (a) R. K. Thomson, B. L. Scott, D. E. Morris and J. L. Kiplinger, C. R. Chim., 2010, 13, 790; (b) R. K. Thomson, C. R. Graves, B. L. Scott and J. L. Kiplinger, Dalton Trans., 2010, 39, 6826; (c) T. Cantat, C. R. Graves, K. C. Jantunen, C. J. Burns, B. L. Scott, E. J. Schelter, D. E. Morris, P. J. Hay and J. L. Kiplinger, J. Am. Chem. Soc., 2008, 130, 17537; (d) D. J. Hilton, R. P. Prasankumar, E. J. Schelter, V. K. Thorsmolle, S. A. Trugman, A. P. Shreve, J. L. Kiplinger, D. E. Morris and A. J. Taylor, J. Phys. Chem. A, 2008, 112, 7840; (e) E. J. Schelter, P. Yang, B. L. Scott, J. D. Thompson, R. L. Martin, P. J. Hay, D. E. Morris and J. L. Kiplinger, Inorg. Chem., 2007, 46, 7477; $(f)$ R. E. Da Re, K. C. Jantunen, J. T. Golden, J. L. Kiplinger and D. E. Morris, J. Am. Chem. Soc., 2005, 127, 682; (g) A. E. Clark, R. L. Martin, P. J. Hay, J. C. Green, K. C. Jantunen and J. L. Kiplinger, J. Phys. Chem. A, 2005, 109, 5481; (h) D. E. Morris, R. E. Da Re, 
K. C. Jantunen and I. Castro-Rodríguez, Organometallics, 2004, 23, 5142.

9 L. Petit, A. Borel, C. Daul, P. Maldivi and C. Adamo, Inorg. Chem., 2006, 45, 7382.

10 For leading references see: (a) P. L. Arnold, Z. Turner, N. Kaltsoyannis, P. Pelekanaki, R. Bellabarba and R. Tooze, Chem.-Eur. J., 2010, 16, 9623; (b) M. J. Tassell and N. Kaltsoyannis, Dalton Trans., 2010, 39, 6719; (c) J. A. Bradley, S. SenGupta, G. T. Seidler, K. T. Moore, M. W. Haverkort, G. A. Sawatzky, S. D. Conradson, D. L. Clark, S. A. Kozimor and K. S. Boland, Phys. Rev. B: Condens. Matter Mater. Phys., 2010, 81, 193104; (d) S. A. Kozimor, P. Yang, E. R. Batista, K. S. Boland, C. J. Burns, D. L. Clark, S. D. Conradson, R. L. Martin, M. P. Wilkerson and L. E. Wolfsberg, J. Am. Chem. Soc., 2009, 131, 12125; (e) L. Maron, O. Eisenstein and R. A. Andersen, Organometallics, 2009, 28, 3629; (f) K. I. M. Ingram, M. J. Tassell, A. J. Gaunt and N. Kaltsoyannis, Inorg. Chem., 2008, 47, 7824; (g) R. G. Denning, J. Phys. Chem. A, 2007, 111, 4125; (h) I. D. Prodan, G. E. Scuseria and R. L. Martin, Phys. Rev. B: Condens. Matter Mater. Phys., 2007, 76, 033101; (i) K. I. M. Ingram, N. Kaltsoyannis, A. J. Gaunt and M. P. Neu, J. Alloys Compd., 2007, 444-445, 369; (j) A. J. Gaunt, S. D. Reilly, A. E. Enriquez, B. L. Scott, J. A. Ibers, P. Sekar, K. I. M. Ingram, N. Kaltsoyannis and M. P. Neu, Inorg. Chem., 2007, 46, 29; (k) C. J. Burns and M. S. Eisen, in The Chemistry of the Actinide and Transactinide Elements, ed. L. R. Morss, N. M. Edelstein and J. Fuger, Springer, Dordrecht, The Netherlands, 3rd edn, 2006, Vol. 5, p. 2799; (l) R. G. Denning, J. C. Green, T. E. Hutchings, C. Dallera, A. Tagliaferri, K. Giarda, N. B. Brookes and L. J. Braicovich, Chem. Phys., 2002, 117, 8008; (m) M. Mazzanti, R. L. Wietzke, J. Pecaut, J.-M. Latour, P. Maldivi and M. Remy, Inorg. Chem., 2002, 41, 2389; (n) B. B. Iversen, F. K. Larsen, A. A. Pinkerton, A. Martin, A. Darovsky and P. A. Reynolds, Inorg. Chem., 1998, 37, 4559; (o) J. Li and B. E. Bursten, J. Am. Chem. Soc., 1997, 119, 9021; $(p)$ J. G. Brennan, R. A. Andersen and J. L. Robbins, J. Am. Chem. Soc., 1986, 108, 335; (q) M. L. Neidig, D. L. Clark and R. L. Martin, Coord. Chem. Rev., 2013, 257, 394.

11 For recent references see (a) M. J. Hudson, L. M. Harwood, D. M. Laventine and F. W. Lewis, Inorg. Chem., 2012, DOI: 10.1021/ic3008848; (b) A. E. V. Gorden, M. A. DeVore II and B. A. Maynard, Inorg. Chem., 2012, DOI: 10.1021/ic300887p; (c) D. Girnt, P. W. Roesky, A. Geist, C. M. Ruff, P. J. Panak and M. A. Denecke, Inorg. Chem., 2010, 49, 9627; (d) Z. Kolarik, Chem. Rev., 2008, 108, 4208; (e) C. Madic, B. Boullis, P. Baron, F. Testard, M. J. Hudson, J.O. Liljenzin, B. Christiansen, M. Ferrando, A. Facchini, A. Geist, G. Modolo, A. G. Espartero and J. De Mendoza, J. Alloys Compd., 2007, 444-445, 23; (f) L. Petit, C. Daul, C. Adamo and P. Maldivi, New J. Chem., 2007, 31, 1738; $(g)$ L. Petit, C. Adamo and P. Maldivi, Inorg. Chem., 2006, 45, 8517; $(h)$ G. R. Choppin and K. L. Nash, Radiochim. Acta, 1995, 70-71, 225.

12 N. Kaltsoyannis, Inorg. Chem., 2012, DOI: 10.1021/ ic3006025.

13 B. M. Gardner, W. Lewis, A. J. Blake and S. T. Liddle, Inorg. Chem., 2011, 50, 9631.
14 O. Maury, M. Ephritikhine, M. Nierlich, M. Lance and E. Samuel, Inorg. Chim. Acta, 1998, 279, 210.

15 D. D. Schnaars, G. Wu and T. W. Hayton, Dalton Trans., 2009, 3681.

16 (a) B. S. Newell, T. C. Schwaab and M. P. Shores, Inorg. Chem., 2011, 50, 12108; (b) I. Castro-Rodríguez, K. Olsen, P. Gantzel and K. Meyer, J. Am. Chem. Soc., 2003, 125, 4565; (c) J. D. Rinehart, T. D. Harris, S. A. Kozimor, B. M. Bartlett and J. R. Long, Inorg. Chem., 2009, 48, 3382; (d) O. P. Lam, C. Anthon, F. W. Heinemann, J. M. Connor and K. Meyer, J. Am. Chem. Soc., 2008, 130, 6567; (e) M. J. Monreal, C. T. Carver and P. L. Diaconescu, Inorg. Chem., 2007, 46, 7226; (f) Y. L. Lai, R. K. Chiang, K. H. Lii and S. L. Wang, Chem. Mater., 2008, 20, 523; (g) L. Salmon, P. Thuery, E. Riviere, S. Miyamoto, T. Yamato and M. Ephritikhine, New J. Chem., 2006, 30, 1220; (h) G. Nocton, F. Burdet, J. Pecaut and M. Mazzanti, Angew. Chem., Int. Ed., 2007, 46, 7574; (i) G. Nocton, J. Pecaut and M. Mazzanti, Angew. Chem., Int. Ed., 2008, 47, 3040; (j) S. Fortier, B. C. Melot, G. Wu and T. W. Hayton, J. Am. Chem. Soc., 2009, 131, 15512; (k) E. J. Schelter, D. E. Morris, B. L. Scott, J. D. Thompson and J. L. Kiplinger, Inorg. Chem., 2007, 46, 5528.

17 J. P. Day and L. M. Venanzi, J. Chem. Soc. A, 1966, 197.

18 K. Krämer, H. U. Güdel, G. Meyer, T. Heuer, N. N. Edelstein, B. Jung, L. Keller, P. Fischer, E. Zych and J. Drozdzynski, Z. Anorg. Allg. Chem., 1994, 620, 1339.

19 G. Bombieri, D. Brown and C. Mealli, J. Chem. Soc., Dalton Trans., 1976, 2025.

20 R. D. Shannon, Acta Cryst., 1976, A32, 751.

21 S. G. Minasian, J. M. Keith, E. R. Batista, K. S. Boland, D. L. Clark, S. D. Conradson, S. A. Kozimor, R. L. Martin, D. E. Schwarz, D. K. Shuh, G. L. Wagner, M. P. Wilkerson, L. E. Wolfsberg and P. Yang, J. Am. Chem. Soc., 2012, 134, 5586.

22 C. Schulzke, Dalton Trans., 2009, 6683.

23 F. Ossola, P. Zanella, P. Ugo and R. Seeber, Inorg. Chim. Acta, 1988, 147, 123.

24 C. Clappe, D. Leveugle, D. Hauchard and G. Durand, J. Electroanal. Chem., 1998, 448, 95.

$25 \mathrm{UCl}_{4}$ dissolved in THF exists as the monomeric tris THF adduct in dilute conditions/optically dilute conditions. See: A. I. Komyak, A. P. Zazhogin, D. S. Umreiko and A. A. Lugovsky, J. Appl. Spectrosc., 2009, 76, 167 and W. G. van der Sluys, J. M. Berg, D. Barnhardt and N. N. Sauer, Inorg. Chim. Acta, 1993, 204, 251.

26 (a) R. A. Satten, C. L. Schreiber and E. Y Wong, J. Chem. Phys., 1965, 42, 162; (b) W. Wagner, N. Edelstein, B. Whittaker and D. Brown, Inorg. Chem., 1977, 16, 1021; (c) M. Karbowiak, A. Mech and J. Drożdżyński, Chem. Phys., 2005, 308, 135.

27 (a) C. Danilo, V. Vallet, J. -P. Flament and U. Wahlgren, J. Chem. Phys., 2008, 128, 154310; (b) I. Infante, E. Eliav, M. J. Vilkas, Y. Ishikawa, U. Kaldor and L. Visscher, J. Chem. Phys., 2007, 127, 124308.

28 (a) J. L. Ryan, Inorg. Chem., 1964, 3, 211; (b) E. Bossé, C. Den Auwer, C. Berthon, P. Guilbaud, M. S. Grigoriev, S. Nikitenko, C. Le Naour, C. Cannes and P. Moisy, Inorg. Chem., 2008, 47, 5746.

29 At the time of publishing this manuscript, one of us also reported the optical properties of U(IV) encapsulated in the 
tetraazamacrocyle DO3A in degassed $\mathrm{MeOH}$ and $\mathrm{DMF}$ in which the absorption and emission spectra are comparable to those reported here; L.S. Natrajan, Dalton Trans., 2012, 41, 13167.

30 See for example R. J. Baker, E. Hashem, M. Motevalli, H. V. Ogilvie and A. Walshe, Z. Anorg. Allg. Chem., 2010, 653, 443.

31 B. Roos, P. R. Taylor and P. E. M. Siegbahn, Chem. Phys., 1980, 48, 157.

32 G. Karlström, et al., Comput. Mater. Sci., 2003, 28, 222.

33 K. Anderson, P.-Å. Malmqvist, B. O. Roos, A. J. Sadlej and K. Wolinskit, J. Phys. Chem., 1990, 94, 5483.

34 K. Pierloota and E. van Besien, J. Chem. Phys., 2005, 123, 204309.

35 P.-Å. Malmqvist, B. O. Roos and B. Schimmelpfennig, Chem. Phys. Lett., 2002, 357, 230.

36 T. Cantat, B. L. Scott and J. L. Kiplinger, Chem. Commun., 2010, 46, 919.

37 Photoluminescence from $\left[\mathrm{Th}\left(\mathrm{PO}_{3} \mathrm{C}_{6} \mathrm{H}_{4} \mathrm{CO}_{2} \mathrm{H}\right) \mathrm{F}_{2}\right]$ has been reported, but it arises from the ligand. P. O. Adelani and $\mathrm{T}$. E. Albrecht-Schmitt, Inorg. Chem., 2010, 49, 5701.

38 For recent reviews see $(a)$ G. Schreckenbach and G. A. Shamov, Acc. Chem. Res., 2010, 43, 19; (b) L. Gagliardi and B. O. Roos, Chem. Soc. Rev., 2007, 36, 893; (c) N. Kaltsoyannis, Chem. Soc. Rev., 2003, 32, 9; I. Kirker and N. Kaltsoyannis, Dalton Trans., 2011, 40, 124; (d) M. J. Tassell and N. Kaltsoyannis, Dalton Trans., 2010, 39, 6719; (e) D. Wang, W. F. van Gunsterenb and Z. Chai, Chem. Soc. Rev., 2012, 41, 5836.

39 (a) M. J. Tassell and N. Kaltsoyannis, Dalton Trans., 2010, 39, 6719; (b) P. L. Arnold, Z. R. Turner, N. Kaltsoyannis, P. Pelekanaki, R. M. Bellabarba and R. P. Tooze, Chem.Eur. J., 2010, 16, 9623; (c) A. E. Clark, J. L. Sonnenberg, P. J. Hay and R. L. Martin, J. Chem. Phys., 2004, 121, 2563; (d) L. Petit, L. Joubert, P. Maldivi and C. Adamo, J. Am. Chem. Soc., 2006, 128, 2190; (e) I. Kirker and N. Kaltsoyannis, Dalton Trans., 2011, 40, 124; (f) B. M. Gardner, D. Patel, A. D. Cornish, J. McMaster, W. Lewis, A. J. Blake and S. T. Liddle, Chem.-Eur. J., 2011, 17, 11266; (g) V. Vallet, U. Wahlgren and I. Grenthe, J. Phys. Chem. A, 2012, 116, 12373.

40 G. A. Bain and J. F. Berry, J. Chem. Educ., 2008, 85, 532-536.

41 G. M. Sheldrick, SHELXL-97, University of Göttingen, Göttingen, Germany, 1998.

42 J. L. Kiplinger, D. E. Morris, B. L. Scott and C. J. Burns, Organometallics, 2002, 21, 5978.

43 D. Brown, J. Chem. Soc. A, 1966, 766.

44 (a) A. D. Becke, Phys. Rev. A, 1988, 38, 3098-100; (b) J. P. Perdew, Phys. Rev. B, 1986, 33, 8822-24.

45 F. Weigend and R. Ahlrichs, Phys. Chem. Chem. Phys., 2005, 7, 3297.
46 Turbomole v5.10, R. Ahlrichs, M. Baer, M. Haeser, H. Horn and C. Koelmel, Chem. Phys. Lett., 1989, 162, 165.

47 Gaussian 09, Revision B.01, M. J. Frisch, G. W. Trucks, H. B. Schlegel, G. E. Scuseria, M. A. Robb, J. R. Cheeseman, G. Scalmani, V. Barone, B. Mennucci, G. A. Petersson, H. Nakatsuji, M. Caricato, X. Li, H. P. Hratchian, A. F. Izmaylov, J. Bloino, G. Zheng, J. L. Sonnenberg, M. Hada, M. Ehara, K. Toyota, R. Fukuda, J. Hasegawa, M. Ishida, T. Nakajima, Y. Honda, O. Kitao, H. Nakai, T. Vreven, J. A. Montgomery Jr., J. E. Peralta, F. Ogliaro, M. Bearpark, J. J. Heyd, E. Brothers, K. N. Kudin, V. N. Staroverov, T. Keith, R. Kobayashi, J. Normand, K. Raghavachari, A. Rendell, J. C. Burant, S. S. Iyengar, J. Tomasi, M. Cossi, N. Rega, J. M. Millam, M. Klene, J. E. Knox, J. B. Cross, V. Bakken, C. Adamo, J. Jaramillo, R. Gomperts, R. E. Stratmann, O. Yazyev, A. J. Austin, R. Cammi, C. Pomelli, J. W. Ochterski, R. L. Martin, K. Morokuma, V. G. Zakrzewski, G. A. Voth, P. Salvador, J. J. Dannenberg, S. Dapprich, A. D. Daniels, O. Farkas, J. B. Foresman, J. V. Ortiz, J. Cioslowski and D. J. Fox, Gaussian, Inc., Wallingford CT, 2010.

48 (a) A. D. Becke, J. Chem. Phys., 1993, 98, 5648-52; (b) C. Lee, W. Yang and R. G. Parr, Phys. Rev. B, 1988, 37, 785-89.

49 B. O. Roos, R. Lindh, P.-Å. Malmqvist, V. Veryazov and P.O. Widmark, J. Phys. Chem. A, 2008, 112, 11431-11435.

50 (a) W. J. Hehre, R. Ditchfield and J. A. Pople, J. Chem. Phys., 1972, 56, 2257; (b) T. Clark, J. Chandrasekhar, G. W. Spitznagel and P. V. R. Schleyer, J. Comput. Chem., 1983, 4, 294; (c) P. C. Hariharan and J. A. Pople, Theor. Chim. Acta, 1973, 28, 213.

51 G. Jansen and B. A. Hess, Phys. Rev. A, 1989, 39, 6016-17 and references cited therein.

52 A. E. Reed and F. Weinhold, J. Chem. Phys., 1985, 83, 1736-40.

53 T. Keith, AIMAll http://aim.tkgristmill.com.

54 R. F. W. Bader "Atoms in Molecules-A Quantum Theory", Oxford University Press, Oxford, 1990.

55 T. Kar, J. G. Angyan and A. B. Sannigrahi, J. Phys. Chem. A, 2000, 104, 9953.

56 B. O. Roos, P. R Taylor and P. E. M Siegbahn, Chem. Phys., 1980, 48, 157.

57 G. Karlström et al., MOLCAS: a program package for computational chemistry, Comput. Mater. Sci., 2003, 28, 222.

58 B. O. Roos, R. Lindh, P.-Å. Malmqvist, V. Veryazov and P.O. Widmark, J. Phys. Chem. A, 2004, 108, 2851; B. O. Roos, R. Lindh, P.-Å. Malmqvist, V. Veryazov and P.-O. Widmark, Chem. Phys. Lett., 2005, 409, 295.

59 M. Douglas and N. Kroll, Ann. Phys., 1974, 155, 89; B. Hess, Phys. Rev. A, 1986, 33, 3742. 